\title{
Validation of a Statistical Methodology for Extracting Vegetation Feedbacks: Focus on North African Ecosystems in the Community Earth System Model ${ }^{\mathscr{O}}$
}

\author{
YAN YU \\ Nelson Institute Center for Climatic Research, University of Wisconsin-Madison, Madison, Wisconsin, and \\ Jet Propulsion Laboratory, California Institute of Technology, Pasadena, California \\ MichAEL NOTARO AND FUYAO WANG \\ Nelson Institute Center for Climatic Research, University of Wisconsin-Madison, Madison, Wisconsin \\ JIAFU MAO, XIAOYING SHI, AND YAXING WEI \\ Environmental Sciences Division, and Climate Change Science Institute, Oak Ridge National Laboratory, \\ Oak Ridge, Tennessee
}

(Manuscript received 3 April 2017, in final form 31 October 2017)

\begin{abstract}
Generalized equilibrium feedback assessment (GEFA) is a potentially valuable multivariate statistical tool for extracting vegetation feedbacks to the atmosphere in either observations or coupled Earth system models. The reliability of GEFA at capturing the terrestrial impacts on regional climate is demonstrated here using the National Center for Atmospheric Research Community Earth System Model (CESM), with focus on North Africa. The feedback is assessed statistically by applying GEFA to output from a fully coupled control run. To reduce the sampling error caused by short data records, the traditional or full GEFA is refined through stepwise GEFA by dropping unimportant forcings. Two ensembles of dynamical experiments are developed for the Sahel or West African monsoon region against which GEFA-based vegetation feedbacks are evaluated. In these dynamical experiments, regional leaf area index (LAI) is modified either alone or in conjunction with soil moisture, with the latter runs motivated by strong regional soil moisture-LAI coupling. Stepwise GEFA boasts higher consistency between statistically and dynamically assessed atmospheric responses to land surface anomalies than full GEFA, especially with short data records. GEFA-based atmospheric responses are more consistent with the coupled soil moisture-LAI experiments, indicating that GEFA is assessing the combined impacts of coupled vegetation and soil moisture. Both the statistical and dynamical assessments reveal a negative vegetation-rainfall feedback in the Sahel associated with an atmospheric stability mechanism in CESM versus a weaker positive feedback in the West African monsoon region associated with a moisture recycling mechanism in CESM.
\end{abstract}

\section{Introduction}

Vegetation affects the climate directly through biophysical feedbacks, consisting of moisture, energy, and momentum exchanges with the atmosphere, and indirectly through biogeochemical processes that alter atmospheric $\mathrm{CO}_{2}$ levels (Pielke et al. 1998; Bonan 2002).

Supplemental information related to this paper is available at the Journals Online website: https://doi.org/10.1175/JCLI-D-170220.s1.

Corresponding author: Yan Yu, yan.yu@jpl.nasa.gov
Through the moisture feedback, an increase in evapotranspiration, regulated by the plant stomatal openings, potentially leads to greater atmospheric precipitable water and precipitation, further enhancing plant growth (Shukla and Mintz 1982; Jones 1983; Henderson-Sellers et al. 1995; Pollard and Thompson 1995; Bonan 2002). Through the albedo feedback, variations in vegetation growth alter the surface albedo and radiative fluxes, leading to changes in local temperature, atmospheric stability, and precipitation, and eventually a vegetation response (Charney 1975). This albedo (energy) feedback is pronounced especially in the occurrence of forest-snow or grass-desert transition (Robinson and 
Kukla 1985; Bonan et al. 1992; Betts and Ball 1997; Bonan 2002). According to the momentum feedback, variations in surface roughness associated with vegetation growth cause changes in wind speed, moisture convergence, atmospheric stability, and precipitation, which then affect vegetation growth (Sud and Smith 1985; Sud et al. 1988; Buermann 2002). The dynamic coupling between vegetation and the atmosphere has clear implications for climate variability (Findell et al. 2011; Santanello et al. 2011) and predictability (Koster et al. 2006, 2010, 2011; Guo et al. 2012; Dirmeyer et al. 2013).

The current understanding of biophysical vegetation feedbacks has largely come from running and analyzing coupled vegetation-climate model simulations that have several key limitations. Simulated feedbacks are model dependent, given that climate models largely differ in terms of their numerical schemes, parameterizations, spatial resolution, and simulation lengths. For example, using the fully coupled National Center for Atmospheric Research (NCAR) Community Climate System Model, version 3.5 (CCSM3.5), with dynamic vegetation, Notaro et al. (2011) concluded that reduced vegetation cover leads to an earlier subtropical Chinese monsoon and a delayed, weaker tropical Australian monsoon. In contrast, in the Regional Climate Model, version 4 (RegCM4), reduced LAI leads to diminished rainfall during Australia's premidmonsoon season but not for China (Notaro et al. 2017). The inconsistent findings regarding China's monsoonal response were attributed to CCSM's excessive forest cover and LAI, exaggerated roughness mechanism, and deficient evapotranspiration (ET) response (Notaro et al. 2017). In addition to the model biases, nearly all modeling studies have applied extreme sensitivity experiments, such as a complete replacement of a specific vegetation type with bare ground or another vegetation type, either locally or globally. Such extreme experiments are unrealistic, since vegetation changes are typically heterogeneous and occur over time. Furthermore, the vast majority of modeling studies have focused on the long-term equilibrium response of climate to an imposed vegetation change, rather than the climatic response to intraseasonal-interannual variations in vegetation abundance, despite its importance to short-term climate prediction (Wang et al. 2014). Owing to these limitations in modeling studies, observational studies of land surface feedbacks are critically needed for confirming the model-based findings (O'Brien 1996), which requires the development and validation of a powerful statistical tool for extracting the observed vegetation feedbacks.

Such a statistical tool is also useful for developing metrics to evaluate coupled Earth system models against an observational benchmark and formulate appropriate performance-based model weighting, which will lead to more accurate future projections of regional climate. Climate models vary dramatically in terms of simulated land-atmosphere interactions (Koster et al. 2006, 2010; Liu et al. 2006; Notaro et al. 2011, 2017), and few studies have attempted to validate simulated vegetation feedbacks against observations to give credibility to their findings (Notaro and Liu 2008; Wang et al. 2013, 2014). Indeed, land-atmosphere interactions remain a key source of uncertainty in climate modeling and climate change projections (Flato et al. 2013). Given the substantial uncertainties in the sign and magnitude of projected changes in Sahel rainfall among models from phase 5 of the Coupled Model Intercomparison Project (CMIP5) (Giannini et al. 2008; Roehrig et al. 2013), with most models containing interactive vegetation phenology and some models also containing dynamic vegetation cover, it is necessary to first evaluate the representation of vegetation-climate interactions by these coupled Earth system models against an observational benchmark. Assigning greater weight to models with higher accuracy in terms of their simulated oceanic and terrestrial controls of regional climate is an effective process-based approach to reduce uncertainties in multimodel climate projections, rather than simply weighting models based on their representation of the mean regional climatology.

The statistical tool for extracting the influence of vegetation fluctuations on atmospheric conditions will need to address several key challenges. First, the atmospheric forcing on vegetation is stronger than vegetation's feedback to the atmosphere, making it challenging to isolate the impact of vegetation variability in the presence of large atmospheric internal noise (Kaufmann et al. 2003; Notaro et al. 2006; Liu et al. 2006; Sun and Wang 2012). Second, the statistical method should have an effective way to deal with sampling errors, given that both the observations and coupled model simulations have limited length, especially a concern for short observational and remote sensing products. Third, given that regional climate is affected by variability in both the ocean and land, the covariability between the ocean and land makes it difficult to clearly separate their individual impacts on the atmosphere.

To address the aforementioned challenges in statistically extracting the impact of intra-annual-interannual variability in oceanic or terrestrial forcings on the atmosphere, the generalized equilibrium feedback assessment (GEFA) was developed (Liu et al. 2008; Wen et al. 2010). GEFA is a multivariate statistical method, based on the stochastic climate theory of Hasselmann (1976) and Frankignoul and Hasselmann (1977). The GEFA methodology addresses the local and nonlocal feedbacks simultaneously, which is critical given that vegetation and SST 
anomalies can remotely affect atmospheric conditions (Chen et al. 2012; Wen et al. 2013; Wang et al. 2013, 2014), and demonstrates the capability of separating the individual impacts of different ocean basins and vegetated regions on climate in select regions. Within the fully coupled CCSM3.5, Wang et al. (2014) performed dynamical ensemble experiments, with imposed anomalies of regional LAI across North America, and compared the atmospheric response to that predicted by the statistical GEFA approach. Consistent feedback estimates between the independent statistical and dynamical approaches, in the same climate model, demonstrated GEFA's ability to isolate the impacts of land surface forcings from oceanic forcings. After validating GEFA in the model, the method was applied to observational and remote sensing data to assess controls on North America's observed climate and develop an observational vegetation feedback benchmark against which climate models may be assessed (Wang et al. 2014).

GEFA is characterized by several key strengths (Wang et al. 2013, 2014) but needs further exploration in terms of its applicability and potential improvement. First, it can estimate the impact of individual forcings within a unified framework, particularly suitable for separating oceanic and terrestrial impacts on the regional climate. Second, the method is easily applied to model output or observations, without need for computationally expensive simulations. However, although GEFA's capability at isolating the contribution of terrestrial forcings from oceanic forcings on North America's climate has been successfully validated (Wang et al. 2014), GEFA's applicability to other ecoregions (e.g., semiarid regions and tropical and subtropical regions) has never been demonstrated by previous studies. In addition, semiarid regions, like the Sahel, exhibit strong vegetation-soil moisture-atmosphere coupling (Koster et al. 2004; Green et al. 2017). GEFA is likely to capture the combined impact of coupled fluctuations in vegetation and soil moisture in those regions (Notaro et al. 2008), which needs to be demonstrated with dynamical experiments. Furthermore, the sampling error grows quickly with increasing number of forcings to be assessed by the traditional GEFA method, thereby requiring relatively long data records to achieve reliable feedback estimates (Wang et al. 2014). For example, with only roughly 30 years of remotely sensed vegetation indices, the traditional GEFA exhibits limited credibility in assessing the observed vegetation feedbacks (Wang et al. 2014). The potential for improving the GEFA method, especially reducing the required data length, needs to be explored if observed land-atmosphere interactions are to be assessed.

The current GEFA validation study focuses on vegetation feedbacks across North Africa, over which the vegetation feedbacks have been intensely studied both for the modern climate and paleoclimate using models. North Africa is characterized by pronounced ecological and moisture gradients. The land surface varies remarkably from the tropical Congo rain forest, to steppe vegetation across the Horn of Africa, to savanna and croplands in the Sahel, to the Sahara Desert. The semiarid North African ecoregions (e.g., the Sahel and Horn of Africa) represent global hot spots of landatmosphere coupling (Koster et al. 2004; Notaro and Liu 2008; Green et al. 2017). Charney (1975) introduced the concept of a positive vegetation feedback on rainfall regarding North African desertification, suggesting that a reduction in vegetation cover produces an increase in surface albedo, leading to low-level cooling, increased atmospheric stability, sinking motion, and drying. From a paleoclimate perspective, numerous modeling studies have suggested that positive vegetation-rainfall feedbacks amplify the response of the intensified and extended West African monsoon (WAM) to the orbital forcing changes during in the mid-Holocene (Kutzbach et al. 1996; Doherty et al. 2000; Foley et al. 2003). However, the sign and intensity of land surface feedbacks across North Africa appear to vary with ongoing changes in climate and terrestrial ecosystems (Liu et al. 2007; Notaro and Liu 2008). In the modern climate, by increasing the surface albedo and decreasing evapotranspiration, a reduction in vegetation cover may have amplified and extended the duration of Sahel drought during the 1960s-1980s (Charney 1975; Charney et al. 1977; Zeng et al. 1999; Wang et al. 2004). For example, Wang et al. (2004) simulated an enhanced severity and persistence of ocean-induced Sahel droughts as a result of vegetation dynamics in a coupled climate model. More specifically, land surface anomalies in soil moisture and vegetation cover across the Sahel and WAM region may significantly impact the convective activity and regional circulation, including the African easterly jet (AEJ), by changing the fluxes of heat and moisture, as indicated by prior modeling studies (Klein et al. 2017). However, such model-based interpretations of North African vegetation feedbacks have never been convincingly verified using observational data. Previous studies have investigated the vegetationrainfall feedbacks across the Sahel using a statistical vegetation index simulation, in which the normalized difference vegetation index (NDVI) is expressed as a linear function of lagged local precipitation and temperature (Los et al. 2006), and Granger causality analysis, in which NDVI and precipitation are expressed as a linear function of each other at different time lags (Lee et al. 2015; He and Lee 2016). However, both methods are based on multiple regression, which is not able to deal with highly correlated predictors and cannot isolate terrestrial impacts from oceanic impacts, thereby biasing the assessed terrestrial 


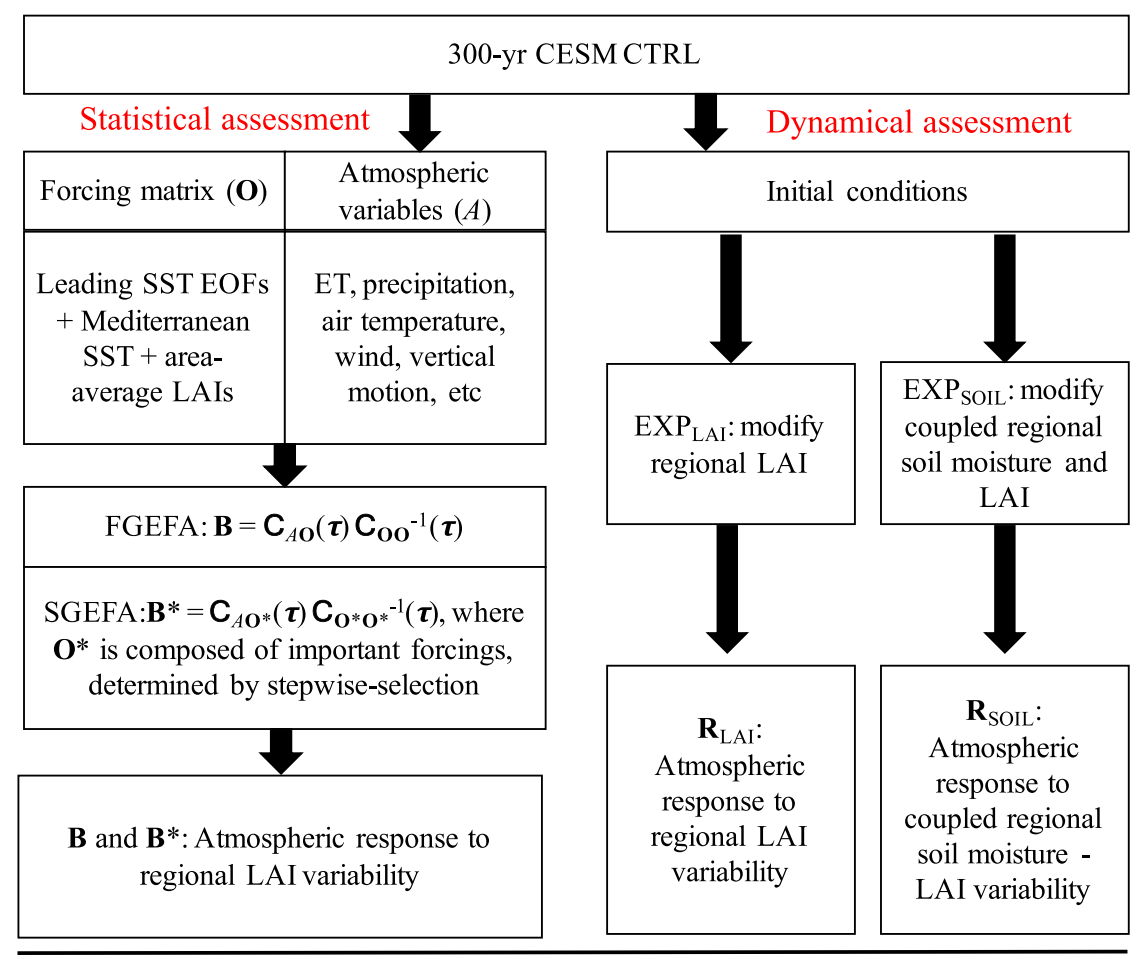

Compare B, B* with $\mathbf{R}_{\mathrm{LAI}}, \mathbf{R}_{\mathrm{SOIL}}$

FIG. 1. Schematic of the current work, including GEFA application to the CESM control run and the dynamical experiments against which GEFA is evaluated. [Equations follow the same notation as applied in Eqs. (1)-(4).]

impacts. Given traditional GEFA's potential capability in extracting vegetation feedbacks from oceanic influence on regional climate, which is largely limited in observational analysis by the short duration of vegetation observations, improving GEFA's reliability, when applied to short data records, and validating its applicability in the North African ecoregions are particularly valuable.

The current study demonstrates the reliability of GEFA at extracting the contribution of terrestrial forcings from oceanic impacts on regional climate through a comparison of statistically and dynamically assessed atmospheric responses to land surface anomalies within the NCAR CESM, with a specific focus on North African ecosystems (approach introduced in section 2 and result presented in section 3). Two ensembles of dynamical experiments modifying regional LAI and coupled soil moisture-LAI, respectively, are developed against which GEFA is evaluated (section $2 b)$. The traditional GEFA approach [section 2a(1)] is refined through stepwise GEFA [section 2a(4)], in which the size of the GEFA forcing matrix is reduced by dropping unimportant drivers and the accuracy of the feedback estimates is improved. We also briefly compared the statistically versus dynamically assessed vegetation-climate feedback mechanisms in CESM across the Sahel and WAM region (section 3d) in order to demonstrate GEFA's capability to offer insight into the physical mechanisms, whether in models or observations. In addition, the current study with CESM provides another example of model-dependent simulated terrestrial feedbacks to motivate a study on observational terrestrial feedbacks against which models can be evaluated. Note that the terrestrial feedbacks presented in the current study are all based on CESM, with inherent model biases, rather than observations.

\section{Method}

In the current study, the capability of GEFA and its refinement, stepwise GEFA, in capturing the terrestrial impacts on North Africa's regional climate is evaluated against two ensembles of dynamical experiments within CESM (Fig. 1). First, GEFA and stepwise GEFA are applied to a 300-yr fully coupled control run (CTRL), yielding statistically assessed atmospheric responses to LAI anomalies in the Sahel and WAM region. Second, two ensembles of dynamical experiments are developed in the Sahel and WAM region, in which either regional 
LAI or coupled soil moisture-LAI is modified, and the dynamically assessed atmospheric responses are treated as the "truth" for evaluating the statistical GEFA method. Assuming the land surface feedbacks vary by month, both the statistical and dynamical assessments of the terrestrial feedbacks are conducted for each calendar month separately, resulting in a seasonal cycle of the assessed land surface feedbacks. By comparing the statistically and dynamically assessed atmospheric responses to LAI anomalies, GEFA's applicability in assessing terrestrial feedbacks across North Africa is evaluated and expected improvements of stepwise GEFA over traditional GEFA are quantified.

\section{a. Traditional and stepwise GEFA}

\section{1) Traditional GEFA}

The statistical GEFA approach [traditional GEFA or full GEFA (FGEFA)] extracts the forcing of a slowly evolving environmental variable, such as SST or LAI, on the rapidly evolving atmosphere, in either climate model output or observational data. GEFA was developed to assess both local and nonlocal climate feedbacks. More details on the GEFA methodology are provided by Liu et al. (2008).

At time scales longer than the atmospheric memory (about one week), the atmospheric variable (e.g., precipitation) at time $t A(t)$ as a response to an array of slowly evolving variables $\mathbf{O}(t)$ (e.g., SST and LAI) can be approximated as follows (Liu et al. 2008):

$$
A(t)=\mathbf{B O}(t)+N(t),
$$

where $\mathbf{B}$ is the feedback vector, and $N(t)$ is the atmospheric internal noise. Multiplying $\mathbf{O}^{\mathrm{T}}(t-\tau)$, which is the transpose of $\mathbf{O}(t-\tau)$, on both sides of Eq. (1) and applying the covariance yields

$$
\mathbf{C}_{A \mathbf{o}}(\tau)=\mathbf{B} \mathbf{C}_{\mathbf{O o}}(\tau)+\mathbf{C}_{N \mathbf{O}}(\tau),
$$

where $\tau$ is the time scale, exceeding the atmospheric adjustment time, and $\mathbf{C}$ is a covariance matrix. Given the time series' length $L$ of the atmospheric and oceanic variables, the lagged covariance matrices are estimated as follows:

$$
\begin{aligned}
& \mathbf{C}_{A \mathbf{O}}(\tau)=\frac{1}{L} A(t) \mathbf{O}^{\mathrm{T}}(t-\tau), \\
& \mathbf{C}_{\mathbf{O O}}(\tau)=\frac{1}{L} \mathbf{O}(t) \mathbf{O}^{\mathrm{T}}(t-\tau), \quad \text { and } \\
& \mathbf{C}_{N \mathbf{O}}(\tau)=\frac{1}{L} N(t) \mathbf{O}^{\mathrm{T}}(t-\tau),
\end{aligned}
$$

The superscript $\mathrm{T}$ indicates a transpose. Since oceanic variability or land surface variability cannot be forced by atmospheric internal variability at a later time and the atmospheric internal noise is not driven by oceanic or land surface forcings by definition in Eq. (1), $\mathbf{C}_{N \mathbf{O}}(\tau)=0$. As a result, the feedback vector can be estimated as

$$
\mathbf{B}=\mathbf{C}_{A \mathbf{O}}(\tau) \mathbf{C}_{\mathbf{O O}}^{-1}(\tau) .
$$

Before applying GEFA, the seasonal cycle and linear trend are removed from all forcing and response fields. The statistical significance of GEFA feedback matrices is assessed using the Monte Carlo bootstrap method with 1000 random iterations in which the time series of the response variable is scrambled, leading to a probability distribution function of the random GEFA feedback coefficients. If the magnitude of the feedback coefficient estimated from the original 300-yr CTRL exceeds the 90th percentile from the 1000 random iterations, the assessed GEFA feedback is regarded as statistically significant $(p<0.1)$ (Wang et al. 2013, 2014).

The estimated feedback vector represents the instantaneous influence of slowly evolving variables (e.g., SST and LAI) on an atmospheric variable. Theoretically, $\mathbf{B}$ does not change with $\tau$, but because of the sampling error (insufficient $L$ ) the magnitude of $\mathbf{B}$ and the sampling error always increase with greater $\tau$. Here, $\tau$ is assigned to be 1 month. Indeed, larger $\tau$ leads to deteriorating estimates of the magnitude of terrestrial feedbacks compared to the dynamical experiments, especially when considering short data records.

\section{2) Fully COUPled CESM CTRL}

The statistical assessment of land surface feedback is performed by applying GEFA to the 300-yr fully coupled CTRL generated with CESM, version 1.2 (Hurrell et al. 2013). The active components in CTRL include the Community Atmosphere Model, version 5.3 (CAM5.3) (Neale et al. 2010); Community Land Model, version 4, with carbon-nitrogen dynamic global vegetation model (CLM4-CNDV) (Oleson et al. 2010; Lawrence et al. 2011); Parallel Ocean Program, version 2 (POP2) (Smith et al. 2010); and Community Ice Code, version 4 (CICE4) (Hunke et al. 2008). The model resolution is $0.9^{\circ}$ latitude $\times$ $1.25^{\circ}$ longitude. CESM successfully captures the mean climatology and interannual variability over the majority of global regions (Hurrell et al. 2013). Potential model biases are identified in the mean climatology and seasonality of LAI and climate variables (see Fig. 4), land-cover type (see Fig. 2), and vegetation feedbacks (see Figs. 7 and 8), but do not affect the approach applied here for GEFA evaluation, since both the statistical and dynamical assessments in the current work are conducted in the same model; consistency between atmospheric response fields from the two assessments, even in the presence of large 
model biases, is sufficient to demonstrate GEFA's reliability. Therefore, the current study does not include a rigorous evaluation of CESM's simulated North African climate and ecosystems against observations.

A 2050-yr offline CLM4-CNDV spinup simulation is first generated to allow terrestrial carbon and nitrogen pools to reach equilibrium, and then the fully coupled control simulation was spun up for another 100 years. At the end of the 2150-yr spinup, the absolute value of globally averaged monthly mean net ecosystem exchange oscillates around $\pm 0.05 \mathrm{PgC} \mathrm{yr}^{-1}$, which is regarded as a sign for equilibrium (Hoffman et al. 2008), with no significant trend in any of the key Earth system variables (e.g., SST, LAI, soil moisture, and fractional cover of plant functional types). The run was extended for another 300 years to serve as the control simulation for GEFA evaluation.

\section{3) COMPOSITION OF GEFA FORCING MATRIX}

In the current application of the statistical GEFA method, both the forcing matrix, comprising SST and LAI fields [O in Eq. (1)], and the atmospheric response variables $[A$ in Eq. (1)] are obtained from the $300-\mathrm{yr}$ CTRL output, leading to a statistical estimation of land surface feedbacks in CESM [feedback coefficients in B associated with LAI forcings in Eq. (4)] (Fig. 1). The GEFA forcing matrix comprises the leading SST empirical orthogonal function (EOF) modes from nonoverlapping ocean basins, area-averaged Mediterranean SSTs, and time series of area-averaged LAI across the Sahel, WAM region, Horn of Africa, and the Congo, generally following the approach of past GEFA studies on terrestrial feedbacks (Wang et al. 2014). The SST EOF modes in each calendar month are extracted from the SST anomalies in that month from the 300-yr CTRL. The corresponding principal components are combined into the forcing matrix $[\mathbf{O}(t)$ in Eqs. (1) and (3)]. The SST forcings at an earlier time $[\mathbf{O}(t-\tau)$ in Eq. (3)] are obtained by projecting the EOF modes to previous SST anomalies (Wang et al. 2017). The main purpose of including oceanic forcings when assessing terrestrial impacts is to tease out any potential contaminations from ocean-land covariability on the estimated terrestrial feedbacks (Sun and Wang 2012). Past modeling studies have suggested the potential impacts of SST variability across the tropical Pacific (TP) (Folland et al. 1986), North Pacific (NP) (Folland et al. 1986), tropical Atlantic (TA) (Giannini et al. 2003; Hoerling et al. 2006), tropical Indian (Lu and Delworth 2005), North Atlantic (Rodríguez-Fonseca et al. 2015), South Pacific (Folland et al. 1986), south Indian (Folland et al. 1986), and South Atlantic Oceans (Folland et al. 1986) and the Mediterranean Sea (Rowell 2003) on the North African climate. For most oceanic basins, the leading two EOF modes have clear physical meanings, such as El Niño-Southern Oscillation (ENSO), the Indian Ocean Basin mode, and the Atlantic Niño mode, and thus are included in the forcing matrix. In addition, higher-order (third-tenth order) SST EOFs that are correlated [i.e. with a temporal correlation of monthly anomalies exceeding $0.2(N=$ 300)] with any of the four LAI time series in the CTRL are also included in the GEFA forcing matrix. Although these higher-order SST EOFs do not exert significant impacts on the North African climate and are rarely selected by stepwise GEFA (SGEFA), including them in the forcing matrix guarantees that the assessed terrestrial feedbacks are not biased by any potential land-ocean covariability. Details on the oceanic forcings in the CESM CTRL and oceanic impacts on the North African climate in CESM are discussed by Wang et al. (2017), who also evaluate GEFA's reliability at capturing the key oceanic impacts on North African climate. In terms of the terrestrial forcings (Fig. 2), the four ecoregions represent different North African landscapes in CESM, varying from mainly forest in the Congo and WAM region to a combination of forests, shrublands, and grasslands in the Sahel and Horn of Africa. The geographic extent of the four ecoregions is determined through rotated EOF (REOF) analysis of monthly LAI anomalies in the CTRL (Fig. 2).

\section{4) STEPwise GEFA}

To achieve reliable estimates of the feedbacks with relatively short datasets, it is necessary to reduce the list of forcings before estimating the feedback vector. Here, negligible forcings are excluded using either backward elimination or forward selection stepwise methods (Hocking 1976), which build a statistical prediction model by selecting the most important forcings as predictors of the atmospheric variable through an automated procedure. The stepwise selection has been widely applied to predictor selection in developing linear models as prediction tools for the climate or ecosystems (Yin et al. 2014; Segele et al. 2015; Yu et al. 2015). The Akaike information criterion (AIC) (Akaike 1974), which measures the relative quality of a statistical model by estimating the goodness of fit and penalizing the complexity of the model (number of predictors), is used here as the selection criterion in the stepwise process:

$$
\begin{aligned}
\mathrm{AIC} & =2 N_{f}-2 \ln (\hat{L}), \\
\hat{L} & =-\frac{L}{2} \ln \left\{\sum_{t=1}^{L}[\hat{A}(t)-A(t)]^{2} / L\right\}+C_{1}, \quad \text { and } \\
\hat{A}(t) & =\mathbf{B O}(t) .
\end{aligned}
$$

In Eq. (5), $N_{f}$ represents the number of forcings in the forcing matrix, and $\hat{L}$ represents the maximized 
(a) REOF 1 (Congo),
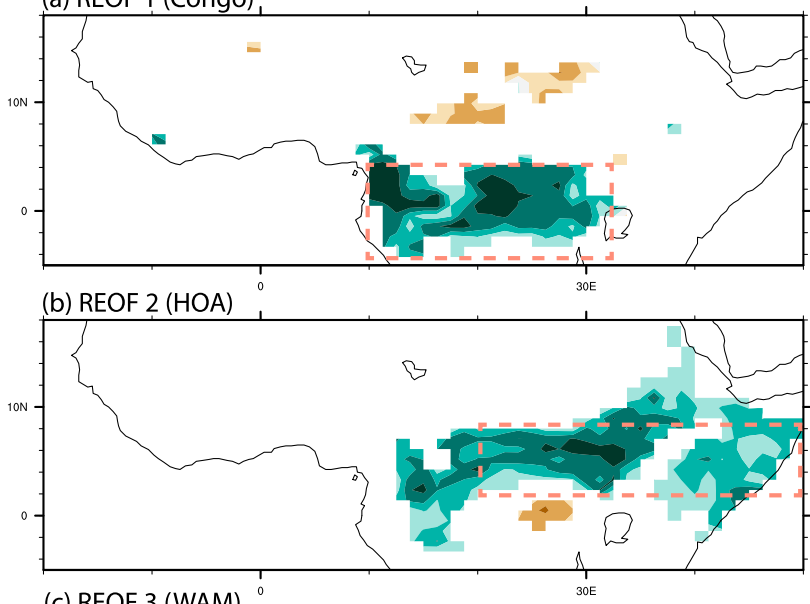

(c) REOF 3 (WAM)

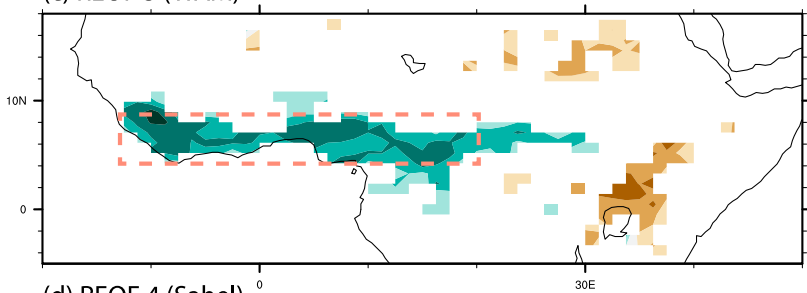

(d) REOF 4 (Sahel)

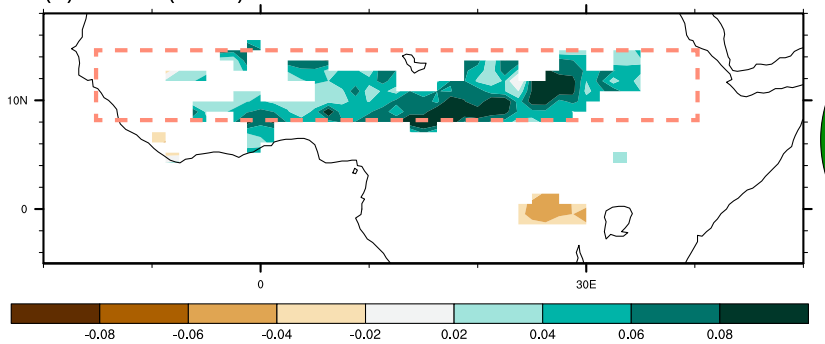

(h) (e)

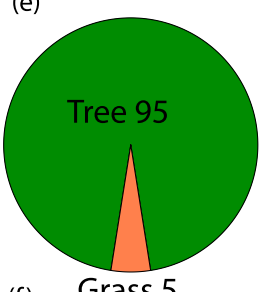

(f) Grass 5

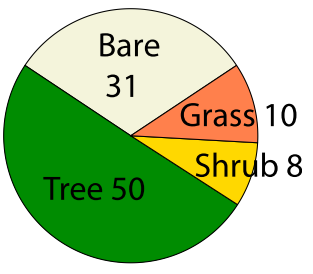

(g)

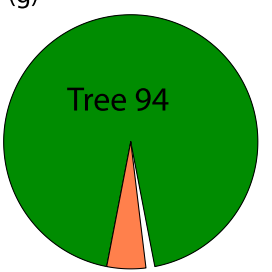

Grass 5

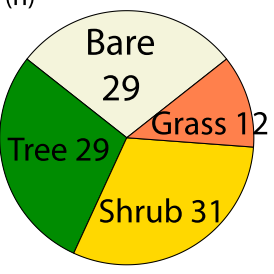

FIG. 2. Spatial pattern of the (a) first, (b) second, (c) third, and (d) fourth leading modes of variability in standardized monthly LAI anomalies from the fully coupled CESM control run, according to REOF analysis. REOF1-REOF4 mainly represent LAI variability across the Congo $\left(4^{\circ} \mathrm{S}-4^{\circ} \mathrm{N}, 10^{\circ}-33^{\circ} \mathrm{E}\right)$, broader Horn of Africa $\left(\mathrm{HOA} ; 2^{\circ}-8^{\circ} \mathrm{N}, 20^{\circ}-50^{\circ} \mathrm{E}\right)$, WAM region $\left(4^{\circ}-8^{\circ} \mathrm{N}, 20^{\circ} \mathrm{W}-20^{\circ} \mathrm{E}\right)$, and the Sahel $\left(8^{\circ}-15^{\circ} \mathrm{N}, 15^{\circ} \mathrm{W}-40^{\circ} \mathrm{E}\right)$, respectively, and combined explain $22.8 \%$ of the total LAI variance. (e)-(h) The pie charts show the mean vegetation distribution per region as a percent cover of tree, shrub, grass, and bare ground in CESM. The REOF analysis helps define regions (red boxes) for area-averaged LAIs to be included in the GEFA forcing matrix. Note that the geographic extent of the four regions in CESM does not cleanly reflect their observed distribution. For example, the simulated Sahel region is about $5^{\circ}$ farther south than observed.

likelihood function of the statistical model in Eq. (1), which represents the likelihood of the statistical model in Eq. (1) with parameters (B vector) estimated from real data by Eq. (4). The $\hat{L}$ in Eq. (5) is calculated by Eqs. (6) and (7), based on the linear theory (Wonnacott and Wonnacott 1972). In Eq. (6), $L$ stands for the length of data, and $C_{1}$ is a constant value independent of the data or $\mathbf{B}$ estimates. In Eq. (7), $\hat{A}(t)$ refers to the predicted atmospheric state at time $t$, based on Eq. (1). In the current study, both backward elimination and forward selection methods are examined for the stepwise selection process to assess robustness in the selected forcings and atmospheric responses. In the backward elimination approach, if the AIC decreases after removing a select forcing, then this forcing has no significant contribution to explaining the variability of the atmospheric variable and can be eliminated from the forcing matrix. The procedure of backward stepwise selection continues until the AIC does not decrease after removing any of the remaining forcings. Similarly, in the forward stepwise selection, forcings are incrementally added to the forcing matrix until the AIC does not 
decrease after adding any of the remaining forcings. Although both forward and backward methods produce largely the same selected forcings in the current study, the application of both methods ensures the robustness of the forcing matrix. After the stepwise selection, the feedback vector is estimated by Eq. (4) using the reduced forcing matrix. In this way, the number of forcings to be assessed by GEFA is reduced, thereby allowing more reliable estimates of feedbacks from the remaining, significant forcings. For example, the original forcing matrix in FGEFA contains 29-41 forcings depending on the analysis month, including two leading SST EOFs from eight basins, Mediterranean SSTs, four areaaveraged LAIs, and third-tenth-order SST EOFs that are significantly correlated with the four area-averaged LAIs. Since the number of higher-order SST EOFs that are correlated with the four North African LAIs differs by month, the total number of forcings included in FGEFA varies by month. When assessing the drivers of Sahel rainfall in CESM, the total number of oceanic and terrestrial forcings is reduced to 5-11 in SGEFA with either backward elimination or forward selection methods (Table $\mathrm{S} 1$ in the supplemental material). Among the selected forcings for Sahel precipitation in SGEFA with both selection methods, $30 \%-100 \%$, varying by month, exert statistically significant impacts $(p<0.1)$ based on the Monte Carlo bootstrap significant test, compared with $10 \%-17 \%$ among the full list of forcings in FGEFA.

In SGEFA, there are several potential ways to examine a forcing of interest that is not chosen by the stepwise selection process. One approach is to require the particular forcing to remain in the forcing matrix by prespecifying it before the stepwise selection, similar to what is usually done in stepwise regression (Hocking 1976). The current study uses this method, since the main objective is to evaluate the statistically assessed terrestrial feedbacks over two focal regions against dynamical experiments that always produce a feedback estimate regardless of its significance. An alternative approach is to treat the particular forcing the same as any other forcing and allow stepwise selection to decide if it is important or not. If the forcing that is of interest is not selected by SGEFA, then the atmospheric response is assigned as zero. The latter method is adopted in the observational study of Sahel vegetation feedbacks, since the decision of stepwise selection to not choose Sahel vegetation as an important forcing of an atmospheric variable suggests that local vegetation feedbacks are not important for that variable (Yu et al. 2017). These two methods yield consistent significance of the assessed terrestrial feedbacks in both the Sahel and WAM region in the current study. For example, when assessing terrestrial feedbacks over the Sahel in CESM, if Sahel LAI is not selected by SGEFA by the second method, then it never achieves statistical significance according to the first method.

\section{b. Dynamical experiments}

To evaluate GEFA's performance in capturing terrestrial impacts on the atmosphere, two ensembles of fully coupled CESM dynamical experiments are created by modifying either LAI $\left(\mathrm{EXP}_{\mathrm{LAI}}\right)$ or coupled soil moisture-LAI (EXP SOIL $)$ across the Sahel or the WAM region. The reasons for choosing both the Sahel and WAM ecoregions are twofold. First, these two regions represent different climate and vegetation types and likely have unique land surface feedbacks (Liu et al. 2010; Notaro et al. 2011). The Sahel is a semiarid region covered by shrublands, forests, grasslands, and bare ground, while the WAM region receives greater annual rainfall and is mainly covered by forests in CESM (Fig. 2). Second, these two ecoregions are geographically close to each other with highly correlated area-averaged LAIs in most months. The correlation of monthly area-averaged LAI anomalies in the Sahel and WAM region in CTRL varies from 0.66 in March to 0.28 in December and has an annual average of 0.52. Although Wang et al. (2013) has demonstrated GEFA's capability of separating significantly correlated oceanic forcings (e.g., ENSO and Indian Ocean Basin mode in winter-spring), GEFA's reliability in separating individual impacts from geographically nearby and statistically correlated vegetation fields has never been evaluated before.

\section{1) $\mathrm{EXP}_{\mathrm{LAI}}$}

An ensemble of 1-month fully coupled dynamical experiments with modified regional LAI $\left(\mathrm{EXP}_{\mathrm{LAI}}\right)$ is created for GEFA validation. In $\mathrm{EXP}_{\mathrm{LAI}}$, in each month, LAI at each grid cell within one of the focal subregions is either increased and fixed to the long-term monthly 95th percentile from CTRL in the positive (LAIINC) experiments or decreased and fixed to the long-term monthly 5th percentile from CTRL in the negative (LAIDEC) experiments (Fig. 3). Ensembles with 30 positive and 30 negative members are created for the Sahel and the WAM region in $\mathrm{EXP}_{\mathrm{LAI}}$ in each month. The ensemble-mean area-averaged LAI anomalies vary from $0.47 \mathrm{~m}^{2} \mathrm{~m}^{-2}$ in August to $1.37 \mathrm{~m}^{2} \mathrm{~m}^{-2}$ in December across the Sahel and from $3.02 \mathrm{~m}^{2} \mathrm{~m}^{-2}$ in May to $4.07 \mathrm{~m}^{2} \mathrm{~m}^{-2}$ in January across the WAM region in LAIINC. The magnitudes of LAI anomalies in LAIDEC are generally slightly smaller than in LAIINC for both regions, since LAI values cannot be lower than zero. 

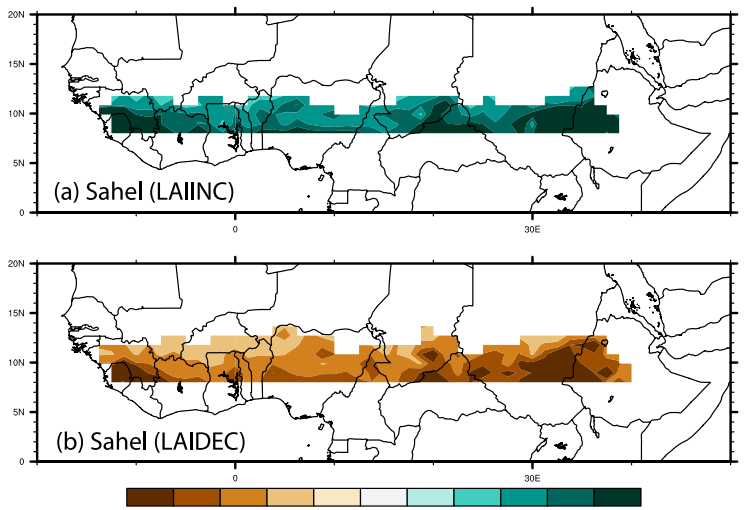

$\begin{array}{llllllllll}-1.5 & -1.2 & -0.9 & -0.6 & -0.3 & 0.3 & 0.6 & 0.9 & 1.2 & 1.5\end{array}$
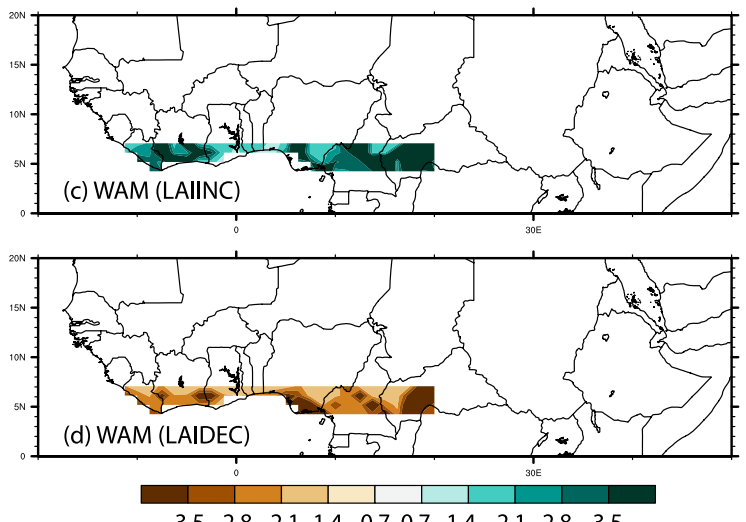

(e) Sahel LAI anomalies

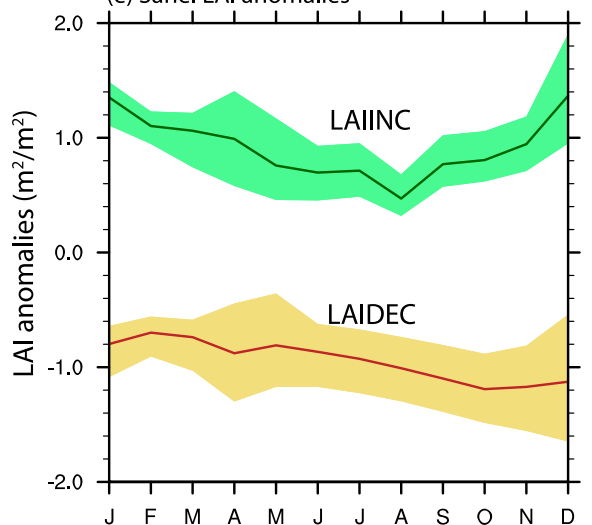

(f) WAM LAI anomalies

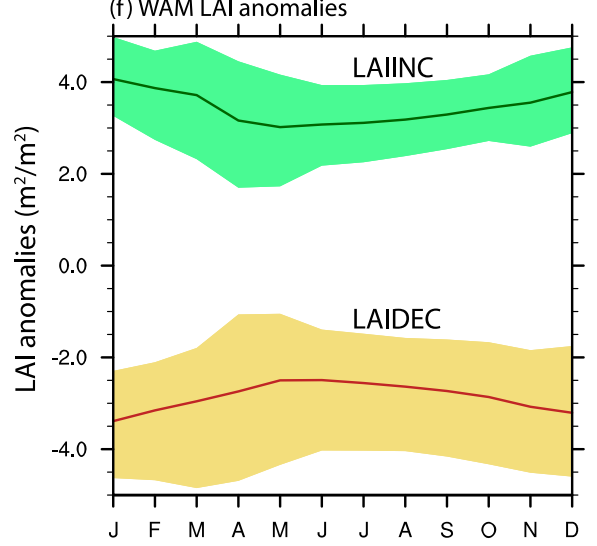

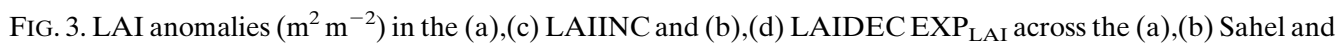
(c),(d) WAM with the (e),(f) seasonal cycle of area-averaged LAI anomalies. Green and brown lines in (e), (f) represent area-averaged LAI anomalies averaged across LAIINC and LAIDEC members, respectively, and the shading denotes the minimum and maximum anomalies among all ensemble members.

The response to the LAI anomalies across a given subregion is represented by the regression coefficient of atmospheric anomalies upon LAI anomalies across the 60 ensemble members (30 LAIINC and 30 LAIDEC) and later compared with the response statistically estimated by GEFA. The statistical significance of the responses is evaluated by the Student's $t$ test. The $90 \%$ confidence interval (5th-95th percentile) is determined through statistical bootstrapping, in which a probability distribution function of the response is generated by randomly sampling 60 out of the 60 ensemble members with replacement for 1000 times (Efron 1982).

\section{2) $\mathrm{EXP}_{\text {SOIL }}$}

In the semiarid regions (e.g., the Sahel) where vegetation and soil moisture are tightly coupled, GEFA feedback estimates will capture the combined impact of coupled fluctuations in vegetation and soil moisture in

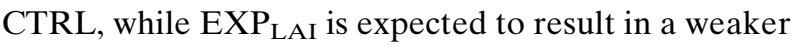

feedback response than GEFA under the positive soil moisture feedback assumption (Koster et al. 2004), since the LAI increase (decrease) in $\mathrm{EXP}_{\mathrm{LAI}}$ is not accompanied by an increase (decrease) in soil moisture (Notaro and Liu 2008; Liu et al. 2010). To address the apparent inconsistency between the GEFA-based and

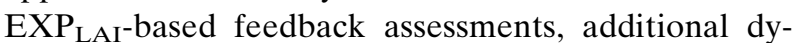
namic experiments, in which both vegetation amount and soil moisture are modified together, are performed in the current study.

Motivated by the strong soil moisture-LAI coupling across North Africa in CESM during the winter-spring dry season, another ensemble of dynamical experiments, in which the coupled soil moisture and LAI are modified together $\left(\mathrm{EXP}_{\text {SOIL }}\right)$, is developed for select months for each focal region. In December, January, March, and April for the Sahel and February and March for the WAM region, the temporal correlation in the CTRL between simulated LAI and antecedent soil moisture within the top $1 \mathrm{~m}$ largely exceeds 0.7 (Fig. 4). 

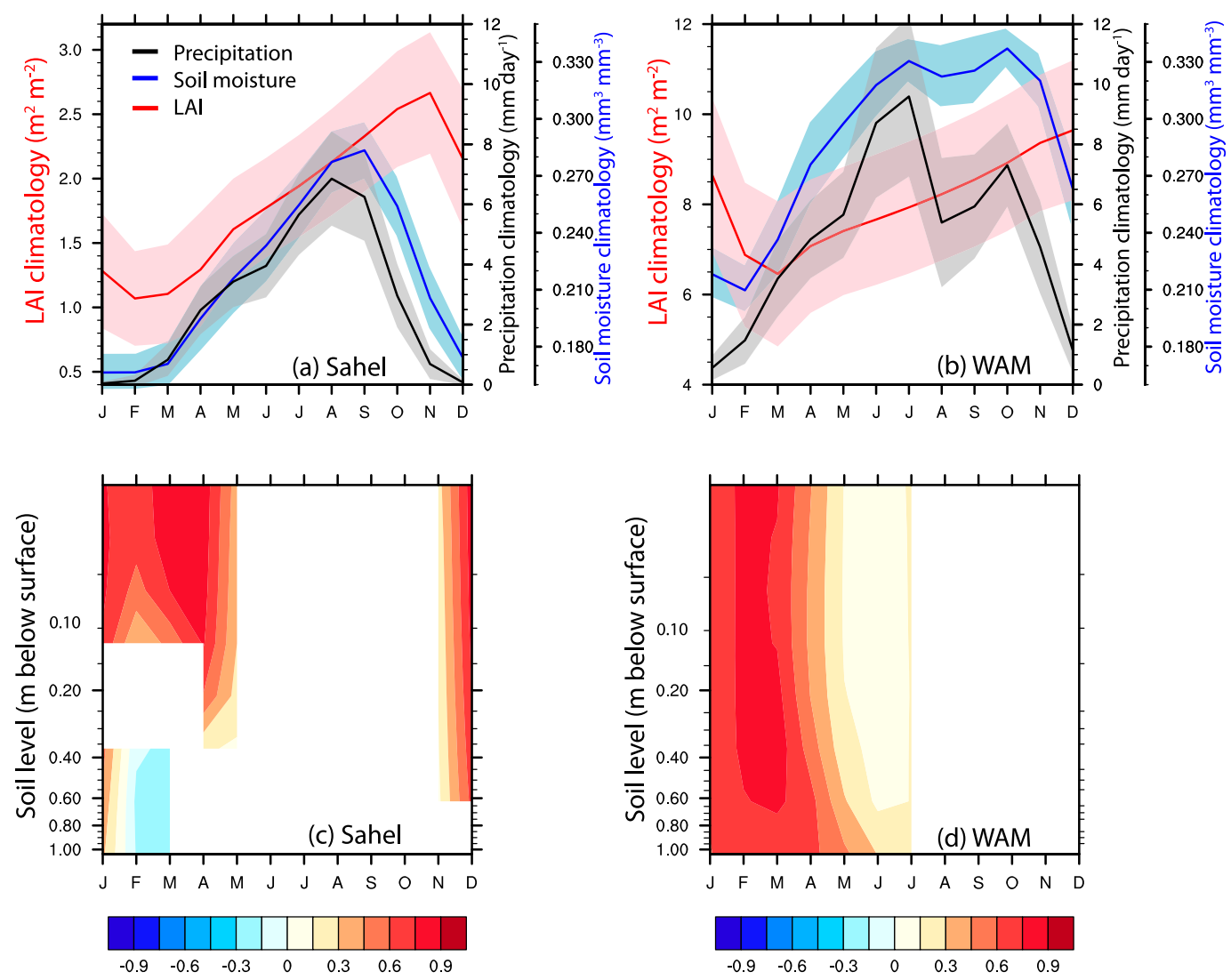

FIG. 4. LAI-soil moisture coupling in CESM. Simulated climatology of area-averaged LAI $\left(\mathrm{m}^{2} \mathrm{~m}^{-2}\right.$; red), nearsurface soil moisture within top $1 \mathrm{~m}\left(\mathrm{~mm}^{3} \mathrm{~mm}^{-3}\right.$; blue) weighted by layer depth, and precipitation $\left(\mathrm{mm} \mathrm{day}^{-1}\right.$; black), with their interannual plus or minus one standard deviation (shading) across the (a) Sahel and (b) WAM. Temporal correlation between area-averaged LAI and previous month's soil moisture by depth across the (c) Sahel

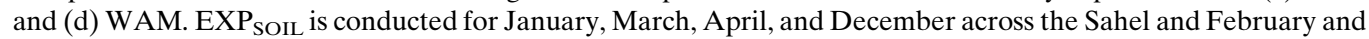
March across WAM, when the correlation between LAI and antecedent soil moisture within the top $1 \mathrm{~m}$ exceeds 0.7. In (c),(d), only significant correlations are shown based on the Student's $t$ test $(p<0.1)$.

During the dry season, water supply is likely the main factor that limits vegetation growth across the study regions, thereby leading to a strong control of the antecedent soil moisture anomalies on the LAI anomalies. In other months, there is no clear relationship between LAI and either the antecedent or current soil moisture across the focal regions. In $\mathrm{EXP}_{\text {SOIL }}$, the initial soil moisture in the focal region is modified, thereby allowing the soil moisture and LAI anomalies to naturally evolve together in 2-month fully coupled runs. In contrast to $\mathrm{EXP}_{\mathrm{LAI}}$ in which the LAI anomalies are fixed during the entire month of simulation, in EXP $_{\text {SOIL }}$ the initial soil moisture is modified and the anomalies in soil moisture and LAI naturally evolve, which takes some time to reach equilibrium. Therefore, 1-month simulations are performed in $\mathrm{EXP}_{\mathrm{LAI}}$, but 2-month simulations are performed in $\mathrm{EXP}_{\mathrm{SOIL}}$. Since the coupled system is unlikely to reach equilibrium in only one to two months, the analyzed responses are not affected by the different long-term equilibrium states in $\mathrm{EXP}_{\text {SOIL }}$ and $\mathrm{EXP}_{\mathrm{LAI}}$.

On the first day of each 2-month run and at each grid cell, soil moisture within the top $1 \mathrm{~m}$ that contains over $70 \%$ of the total root mass in both the Sahel and WAM region is either increased to the long-term 95th percentile from CTRL for the SOILINC experiments or decreased to the long-term 5th percentile from CTRL for the SOILDEC experiments. The anomalously wet (dry) soil initially enhances (inhibits) vegetation growth (Figs. 5a,d), which in turn depletes (augments) the soil moisture within the rooting depth and causes a drying (wetting) trend in the later days (Figs. 5b,e). In the second month of the simulation, the initial soil moisture anomalies are notably reduced compared to the control run, but still significantly more pronounced than in $\mathrm{EXP}_{\text {LAI }}$ (i.e., wetter in SOILINC than in LAIINC and drier in SOILDEC than in LAIDEC) (Figs. 5c,f). Therefore, EXP $\mathrm{ESIL}_{\text {sol }}$ successfully represents the effects 
(a) LAI : Sahel

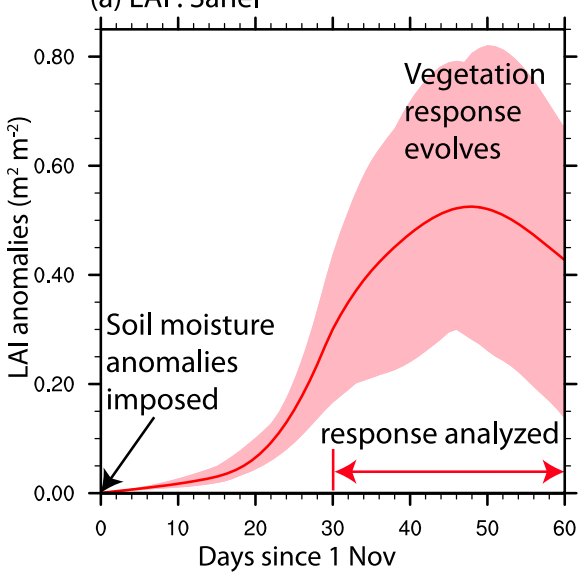

(d) LAI: WAM

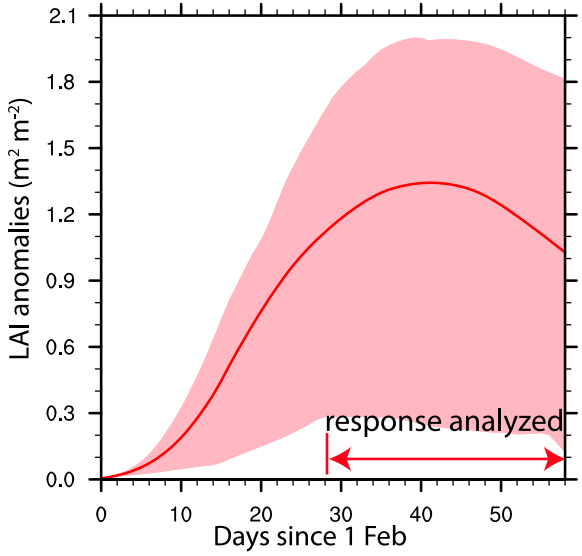

(b) Soil moisture: Sahel

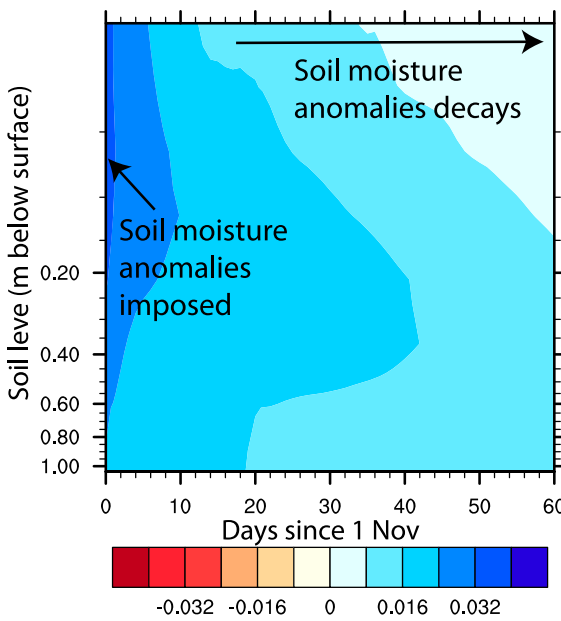

(e) Soil moisture: WAM

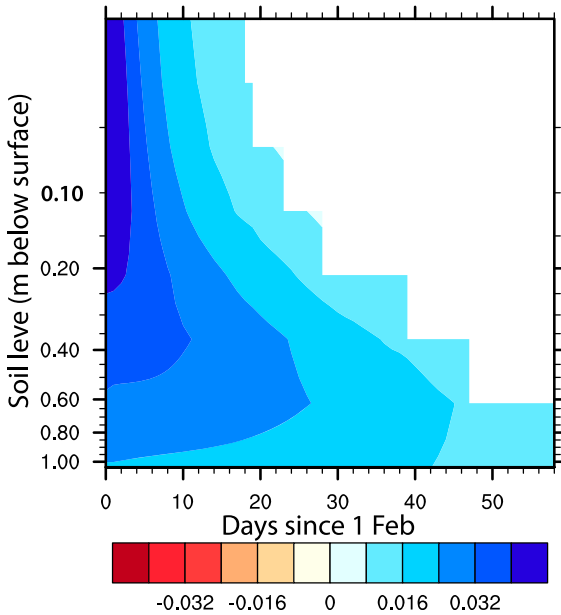

(c) Soil moisture difference: Sahel

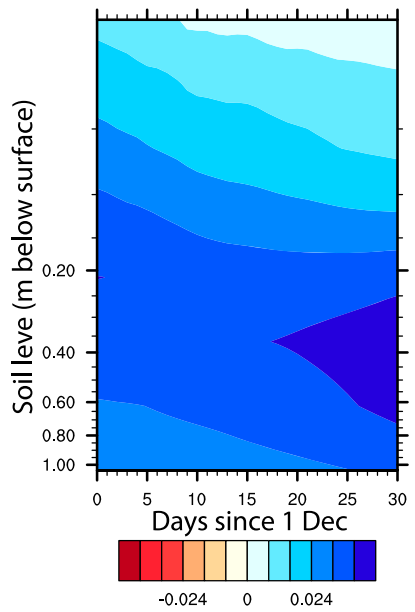

(f) Soil moisture difference: WAM

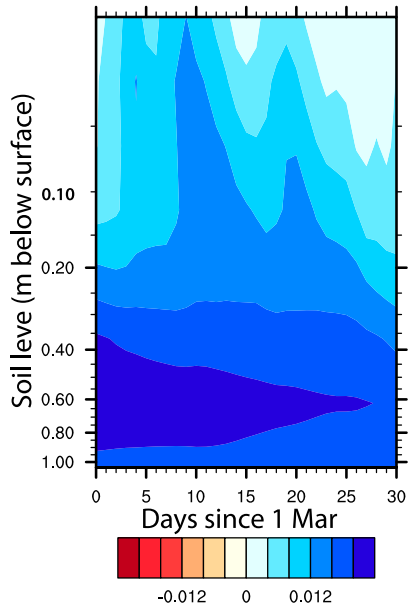

FIG. 5. Evolution of anomalies [(SOILINC - SOILDEC)/2] in (a),(d) LAI $\left(\mathrm{m}^{2} \mathrm{~m}^{-2}\right)$, (b), (e) soil moisture $\left(\mathrm{mm}^{3} \mathrm{~mm}^{-3}\right) \mathrm{across}$ the $(\mathrm{a})$, (b) Sahel since 1 November and (c),(d) WAM since 1 February in EXP SOIL. Evolution of soil moisture responses $\left(\mathrm{mm}^{3} \mathrm{~mm}^{-3} \mathrm{LAI}^{-1}\right)$ in the top $1 \mathrm{~m}$ between soil experiments and LAI experiments [(SOILINC - SOILDEC)/2 - (LAIINC - LAIDEC)/2] across the (c) Sahel since 1 December and (f) WAM since 1 March. The lines in (a),(b) represent ensemble average, and shading represents the minimum and maximum LAI anomalies among all ensemble members. In (b),(c),(e),(f) only significant differences are shown in color based on the Student's $t$ test $(p<0.1)$. Although soil moisture anomalies in soil experiments are not sustained into the second month in WAM, the SOILINC (SOILDEC) experiments produce significantly wetter (drier) soil than the LAIINC (LAIDEC) experiments, which reflects the strong positive coupling between soil moisture and LAI.

of coupled soil moisture-LAI anomalies on the atmosphere by allowing vegetation anomalies to naturally evolve. Atmospheric responses to the coupled soil moisture-LAI anomalies are analyzed in the second month of the experiment, when the soil moisture and LAI anomalies reach equilibrium and LAI anomalies are maximized (Figs. 5a,d).

To directly compare with the statistically assessed feedbacks, the responses in the $\mathrm{EXP}_{\text {SOIL }}$ are represented by the regression coefficient of atmospheric anomalies upon LAI anomalies across the 60 ensemble members (30 SOILINC and 30 SOILDEC). The statistical significance and $90 \%$ confidence interval (5th95th percentile) are obtained similarly as in $\mathrm{EXP}_{\mathrm{LAI}}$.

\section{Results}

\section{a. Local versus nonlocal terrestrial impacts}

Unlike oceanic forcing, which usually exerts significant remote impacts on the atmosphere through teleconnections (Wang et al. 2017), the impacts of terrestrial forcings are mostly local in CESM. For example, in the dynamical experiments with modified Sahel LAI, an annual average of $97 \%$ of significant responses in ET 
TABLE 1. List of key statistics for GEFA evaluation. SGEFA and FGEFA are compared in terms of their consistency with EXP LAI $_{\text {and }}$ $\mathrm{EXP}_{\text {SOIL }}$ in the seasonal cycle (12 values for 12 calendar months) of the assessed local atmospheric responses (within the same geographic box as the LAI anomalies) to LAI anomalies in the Sahel or WAM region. For each focal region, in the months when EXP SOIL conducted the dynamical responses are extracted from $\mathrm{EXP}_{\mathrm{SOIL}}$, or otherwise from $\mathrm{EXP}_{\mathrm{LAI}}$.

\begin{tabular}{ll}
\hline \hline $\begin{array}{l}\text { Temporal correlation } \\
\text { Correlation between the seasonal cycle of local area-averaged responses to Sahel or WAM LAI } \\
\text { anomalies in the dynamical experiments and GEFA }(N=12 \text { months }), \text { reflecting the } \\
\text { general consistency between GEFA and dynamical experiments. }\end{array}$ \\
$\begin{array}{l}\text { Rignal-to-noise ratio } \\
\text { (SNR) } \\
\text { Sign consistency }\end{array}$ \\
$\begin{array}{l}\text { between responses from GEFA and the dynamical experiments, reflecting the magnitude consistency. } \\
\text { experiments are the same (both significantly positive, significantly negative, or insignificant), } \\
\text { reflecting sign consistency. }\end{array}$
\end{tabular}

over land, $89 \%$ in latent heat flux over land and ocean, $88 \%$ in sensible heat flux, $91 \%$ in surface air temperature, and $81 \%$ in precipitation occur within the Sahel box (hereafter referred to as "local responses"). For FGEFA (SGEFA), these numbers are $81 \%$ (89\%), 79\% (92\%), 74\% (90\%), 72\% (87\%), and 69\% (84\%), respectively. Since most of the response to LAI anomalies occurs locally, the evaluation of statistical GEFA mainly focuses on the local atmospheric responses to LAI anomalies across the Sahel or WAM region.

\section{b. Capability of SGEFA versus FGEFA in capturing the seasonal cycle of local responses to LAI anomalies}

In this section, the GEFA evaluation and comparison between SGEFA and FGEFA involves three metrics: temporal correlation, signal-to-noise ratio, and sign consistency (introduced in Table 1).

SGEFA generally performs better than FGEFA in capturing the sign and magnitude of local atmospheric responses to LAI anomalies across the Sahel and WAM region (Fig. 6 and Fig. S1 in the supplemental material). SGEFA yields higher temporal correlations, signal-tonoise ratios (SNRs), and sign consistency than FGEFA, in terms of estimating the seasonal cycle of all variables in response to Sahel LAI anomalies, when compared with the dynamical experiments. The performance of SGEFA is seemingly independent of the choice in stepwise selection method, as both forward and backward selection methods produce nearly identical temporal correlations, SNRs, and sign consistency because of largely identical forcings selected by both methods. Hereafter, all statistics for SGEFA are provided based on backward selection, with minimal relative differences in these evaluation statistics between backward and forward selection approaches [(forward minus backward) divided by forward multiplied by $100 \%$ ] that are always less than $5 \%$. With 300 years of data, the seasonal cycle of the local response estimated by SGEFA is moderately to highly correlated ( $N=12$ months) with that from the dynamical experiments, with a temporal correlation of 0.90 for ET, 0.81 for 2-m air temperature, 0.89 for planetary boundary layer height (PBLH), 0.68 for $2-\mathrm{m}$ specific humidity, 0.74 for $10-\mathrm{m}$ wind, and 0.53 for precipitation, compared with weaker correlations of $0.62,0.71,-0.10,0.03,0.12$, and 0.48 , respectively, from FGEFA. SGEFA apparently causes more substantial improvement over FGEFA in variables that are less directly affected by land surface conditions, such as PBLH, 2-m specific humidity, and 10-m wind, likely due to limited capability of FGEFA in separating terrestrial impacts from oceanic impacts when terrestrial impacts are less direct. In terms of the SNR, the benefits of SGEFA over FGEFA are even more pronounced. With 300 years of data, the SNRs with dynamical experiments in the estimated seasonal cycle of local responses over the Sahel according to SGEFA are 3.3, 2.7, 3.0, 1.4, 2.0, and 1.4 for ET, 2-m air temperature, PBLH, 2-m specific humidity, $10-\mathrm{m}$ wind, and precipitation, respectively, compared with only $2.0,2.4,0.5,0.1,0.7$, and 0.4 , respectively, according to FGEFA. SGEFA also boasts a higher sign consistency than FGEFA with the dynamical experiments, although the benefit is not as pronounced as with the signal-to-noise ratio. With 100 years of data, the relative difference between SGEFA and FGEFA [(SGEFA - FGEFA)/FGEFA $\times 100 \%$ in SNR varies substantially from $105 \%$ to $611 \%$ for different atmospheric variables in Fig. 6, but only $13 \%-50 \%$ in terms of sign consistency. This indicates that SGEFA offers a greater advantage in estimating the magnitude of responses over FGEFA than in estimating the sign of the responses. In estimating responses to LAI anomalies in the WAM region, SGEFA generally outperforms FGEFA as well, but the advantage is less pronounced than with the Sahel, especially in terms of the sign consistency, probably because the atmospheric responses to the WAM LAI anomalies are largely insignificant and small in magnitude (see Fig. 8). Among 

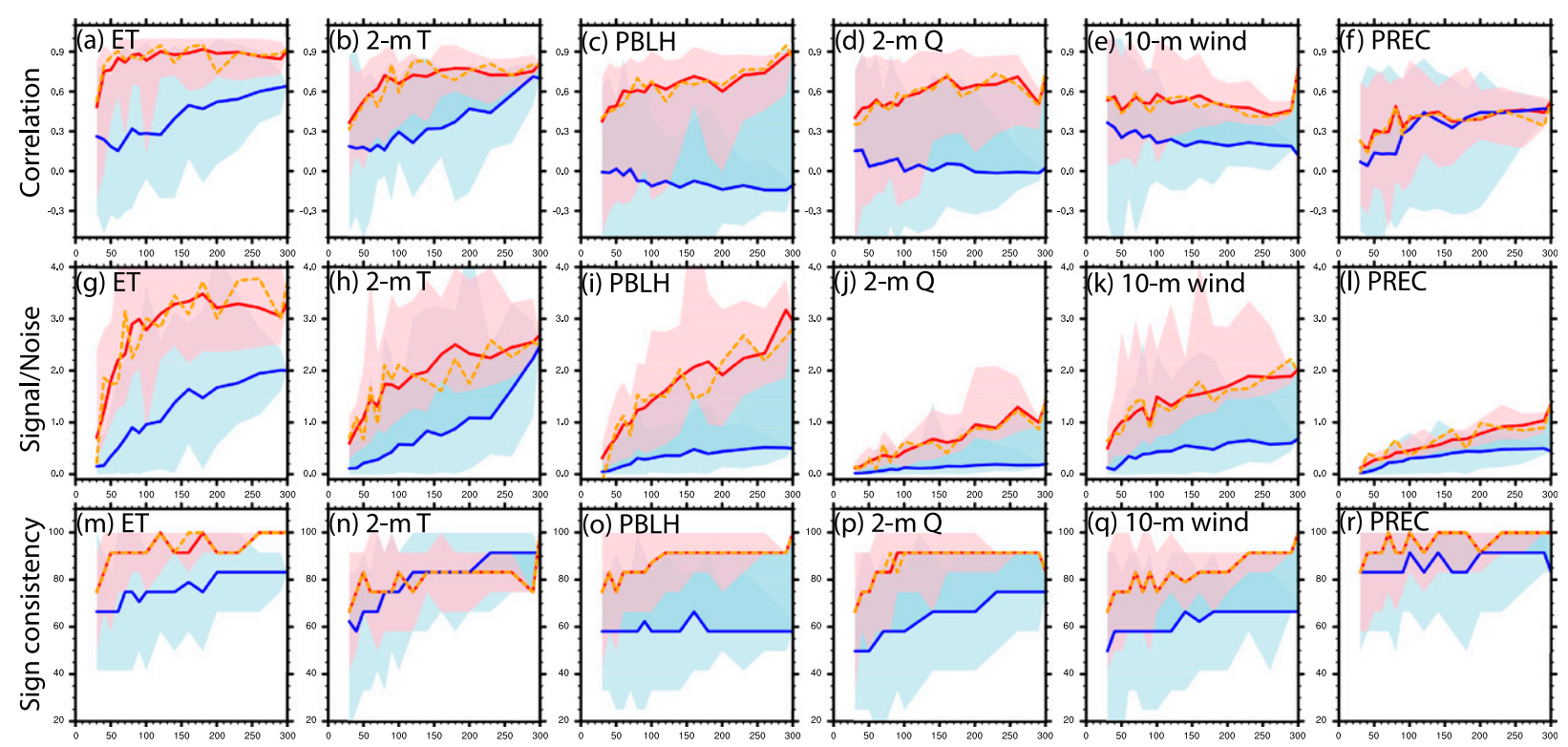

length of record (yrs)

\section{SGEFA-backward SGEFA-forward FGEFA}

FIG. 6. Consistency between statistical GEFA [FGEFA (blue), SGEFA with backward selection (SGEFA-backward; red), and SGEFA with forward selection (SGEFA-forward; dashed orange)] and dynamical experiments (January, March, April, and December from $\mathrm{EXP}_{\text {SOIL }}$; other months from $\left.\mathrm{EXP}_{\mathrm{LAI}}\right)$ in the seasonal cycle $(N=12$ months) of local area-averaged responses to LAI anomalies across the Sahel, in terms of (a)-(f) temporal correlation, (g)-(l) ratio between signal (mean absolute response in dynamical experiment) and noise (root-mean-square difference between GEFA and dynamical experiments), and (m)-(r) sign consistency, as a function of length of record (No. of years) on the $x$ axis. Comparisons are shown for variables with significant responses to Sahel LAI in the dynamical experiment for $10+$ months, including ET, 2-m air temperature (2-m T), PBLH, 2-m specific humidity (2-m $Q)$, 10-m wind speed (10-m wind), and precipitation (PREC), in the order of relative consistency between GEFA and dynamical experiments. Lines (shading) represent the median (minimum and maximum) across different periods over which GEFA is applied. The shading for SGEFA-forward is not included because it is nearly identical to the shading for SGEFA-backward.

the different response variables considered here, both FGEFA and SGEFA obtain the highest accuracy in estimating the response in ET, which is directly affected by LAI and soil moisture. Precipitation responses are one of the most challenging variables to be estimated by GEFA, especially in terms of the response magnitude, likely because precipitation is indirectly affected by vegetation and soil moisture anomalies through multiple mechanisms, some of which are competing against each other (see Fig. 7, discussed later). Partly as a result of the competing vegetationrainfall feedback mechanisms, the precipitation responses are generally small in magnitude according to both GEFA and dynamical experiments, compared with ET, thereby leading to low SNRs and temporal correlations.

Both SGEFA and FGEFA are sensitive to record length, although with significantly shorter data records needed for SGEFA to obtain reliable feedback estimates. For the responses to Sahel LAI anomalies in most variables, when the length of data records is short ( $<100 \mathrm{yr}$, which is the typical length of observations), FGEFA struggles to capture terrestrial impacts, while
SGEFA achieves reasonable sign consistency $(>70 \%)$ and temporal correlation (typically $0.6-0.8 ; N=$ 12 months) for most response variables with the dynamical assessment. To obtain a reliable estimate of the seasonal cycle of local responses with a temporal correlation of 0.7 with the dynamical experiments for Sahel, SGEFA requires approximately 50, 70, 90, 140, 280, and $>300 \mathrm{yr}$ of data for ET, 2-m air temperature, PBLH, 2-m specific humidity, $10-\mathrm{m}$ wind, and precipitation, respectively, compared with at least $290 \mathrm{yr}$ for all variables with FGEFA. Again, precipitation needs relatively long data records to achieve an acceptable temporal correlation between the statistical GEFA assessment and dynamical assessment, mainly because of the small response magnitudes. Indeed, if the target is to achieve a sign consistency of $90 \%$ between SGEFA and dynamical experiments, only $50 \mathrm{yr}$ of precipitation data are needed, which is similar to that of ET. Given the significant improvement of SGEFA compared with FGEFA, the subsequent detailed evaluation against the dynamical experiments focuses only on SGEFA. 

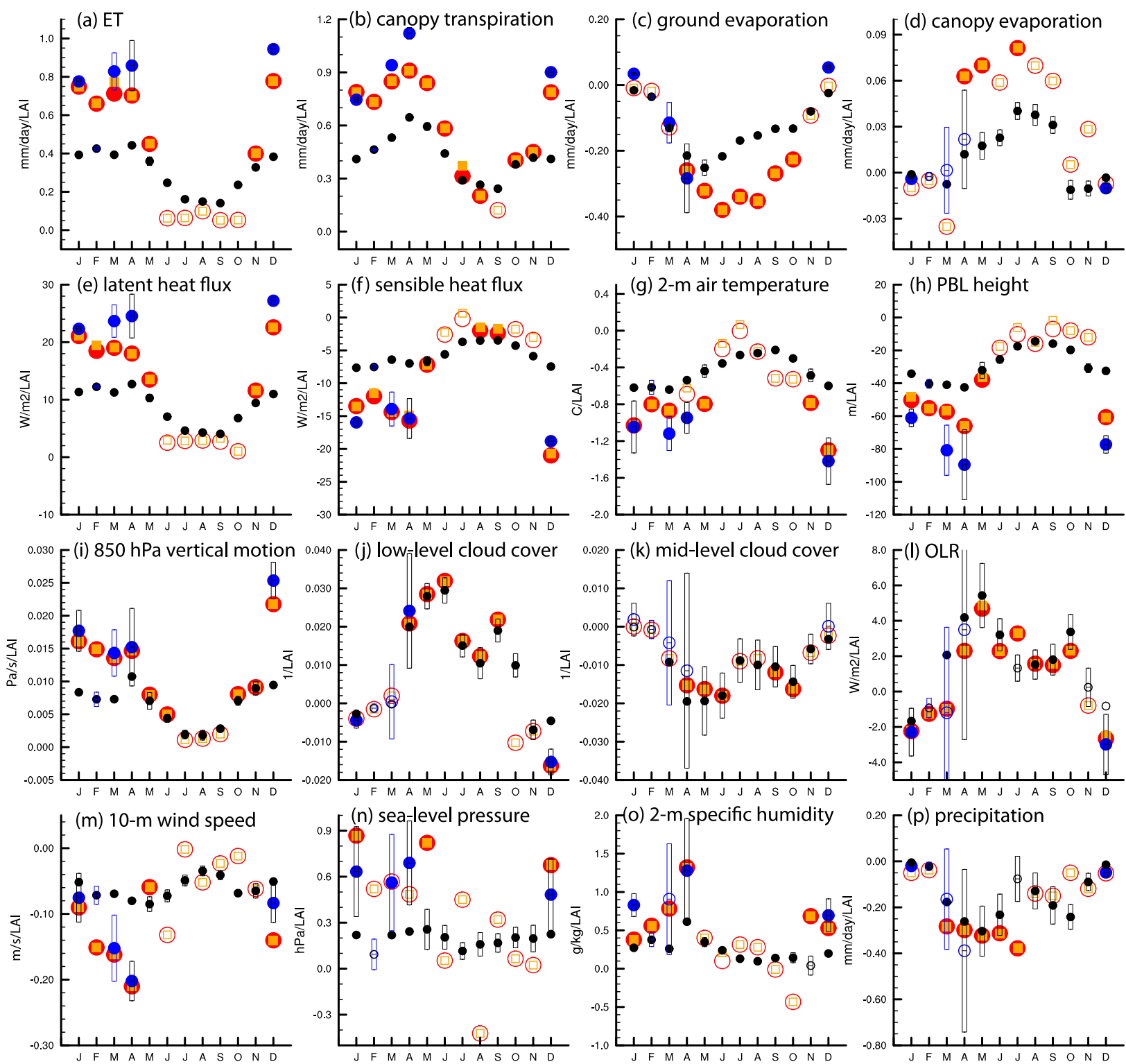

\begin{tabular}{|c|c|c|c|}
\hline \multirow[t]{4}{*}{ Legend } & 0 & O & SGEFA-backward \\
\hline & 口 & $\square$ & SGEFA-forward \\
\hline & - & $\mathrm{O}$ & $\operatorname{EXP}_{\text {SOIL }}$ \\
\hline & 0 & O & $\operatorname{EXP}_{\text {LAl }}$ \\
\hline
\end{tabular}

FIG. 7. Seasonal cycle of local area-averaged responses to LAI anomalies across the Sahel in select variables assessed from EXP $\mathrm{LAI}$

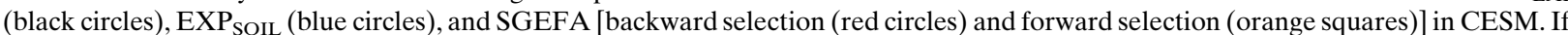
Sahel LAI is not selected by stepwise GEFA, the response is estimated by manually adding Sahel LAI into the forcing matrix. Filled circles and squares indicate statistically significant $(p<0.1)$ responses, according to the Student's $t$ test for the dynamical experiments and Monte Carlo bootstrap test for GEFA. The rectangles represent $90 \%$ confidence interval of the responses from EXP $\mathrm{SOIL}_{\text {(blue) and EXP }}$ LAI $($ black). 
TABLE 2. Local responses in select variables to LAI anomalies across the Sahel and WAM region assessed by EXP $\mathrm{LAI}_{\text {I }}, \mathrm{EXP}_{\mathrm{SOIL}}$, and SGEFA. The responses are averaged during the winter-spring dry season, namely, December, January, March, and April for the Sahel and February and March for the WAM region, which exhibit strong coupling between soil moisture and LAI. Values in boldface indicate if $\mathrm{EXP}_{\mathrm{LAI}}$ or $\mathrm{EXP}_{\mathrm{SOIL}}$ is more consistent with SGEFA.

\begin{tabular}{|c|c|c|c|c|c|c|}
\hline & \multicolumn{3}{|c|}{ Sahel } & \multicolumn{3}{|c|}{ WAM } \\
\hline & $\mathrm{EXP}_{\text {LAI }}$ & $\mathrm{EXP}_{\text {SOIL }}$ & SGEFA & $\mathrm{EXP}_{\text {LAI }}$ & $\mathrm{EXP}_{\text {SOIL }}$ & SGEFA \\
\hline $\mathrm{ET}\left(\mathrm{mm} \mathrm{day}^{-1} \mathrm{LAI}^{-1}\right)$ & 0.40 & 0.85 & 0.74 & 0.11 & 0.27 & 0.20 \\
\hline Latent heat flux $\left(\mathrm{W} \mathrm{m}^{-2} \mathrm{LAI}^{-1}\right)$ & 11.57 & 24.42 & 20.17 & 2.85 & 7.17 & 5.45 \\
\hline Sensible heat flux $\left(\mathrm{W} \mathrm{m}^{-2} \mathrm{LAI}^{-1}\right)$ & -7.12 & -16.02 & -16.14 & -2.69 & -9.11 & -6.12 \\
\hline 2-m air temperature $\left({ }^{\circ} \mathrm{C} \mathrm{LAI}{ }^{-1}\right)$ & -0.60 & -1.13 & -0.97 & -0.1 & -0.19 & -0.16 \\
\hline $\operatorname{PBLH}\left(\mathrm{m} \mathrm{LAI}^{-1}\right)$ & -37.54 & -77.18 & -58.58 & $-\mathbf{1 0 . 5 9}$ & -36.82 & -22.22 \\
\hline 850-hPa vertical motion $\left(\mathrm{Pa} \mathrm{s}^{-1} \mathrm{LAI}^{-1}\right)$ & 0.009 & 0.018 & 0.017 & 0.004 & 0.005 & 0.005 \\
\hline $\operatorname{OLR}\left(\mathrm{W} \mathrm{m}^{-2} \mathrm{LAI}^{-1}\right)$ & 0.94 & -0.75 & -0.89 & 0.87 & -2.01 & -2.27 \\
\hline 10-m wind speed $\left(\mathrm{m} \mathrm{s}^{-1} \mathrm{LAI}^{-1}\right)$ & -0.06 & $-\mathbf{0 . 1 3}$ & -0.15 & -0.02 & -0.05 & -0.04 \\
\hline 2-m specific humidity $\left(\mathrm{g} \mathrm{kg}^{-1} \mathrm{LAI}^{-1}\right)$ & 0.34 & 0.93 & 0.75 & 0.08 & 0.45 & 0.50 \\
\hline Precipitation $\left(\mathrm{mm} \mathrm{day}{ }^{-1} \mathrm{LAI}^{-1}\right)$ & -0.11 & -0.16 & -0.17 & -0.09 & 0.15 & 0.08 \\
\hline
\end{tabular}

\section{c. Consistency of GEFA-based assessment with EXP $P_{\text {SOIL }}$ versus EXP $P_{L A I}$}

GEFA-based atmospheric responses to LAI anomalies are generally consistent with both the $\mathrm{EXP}_{\mathrm{LAI}}$ and $\mathrm{EXP}_{\text {SOIL }}$ ensembles, with higher consistency in both sign and magnitude with the $\mathrm{EXP}_{\text {SOIL }}$ ensemble than the $\mathrm{EXP}_{\mathrm{LAI}}$ ensemble during months with strong soil moistureLAI coupling. For example, in the Sahel, LAI anomalies alone cause a response of $+0.40 \mathrm{~mm} \mathrm{day}^{-1} \mathrm{LAI}^{-1}$ in local ET during the dry season (averaged among December,

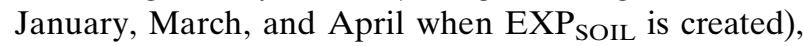
while the coupled soil moisture-LAI anomalies support a greater response of $+0.85 \mathrm{~mm}$ day $^{-1} \mathrm{LAI}^{-1}$ in local ET, compared with $+0.74 \mathrm{~mm}_{\text {day }}{ }^{-1} \mathrm{LAI}^{-1}$ from SGEFA (Fig. 7 and Table 2). In the WAM region, GEFA is more consistent with $\mathrm{EXP}_{\text {SOIL }}$ than $\mathrm{EXP}_{\mathrm{LAI}}$ in both the sign and magnitude of the estimated responses (Fig. 8 and Table 2). For example, a positive LAI anomaly alone in EXP $_{\text {LAI }}$ causes a slight drying in March in the WAM region, while synchronous positive anomalies in LAI and soil moisture in $\mathrm{EXP}_{\text {SOIL }}$ cause a weak increase in precipitation, which is successfully captured by SGEFA in both sign and magnitude. The higher consistency between GEFA and $\mathrm{EXP}_{\text {SOIL }}$, in terms of the estimated response in the majority of variables in both study regions, indicates that GEFA captures the combined impact of coupled LAI and soil moisture anomalies on atmospheric conditions.

\section{d. Terrestrial impacts over the Sahel and WAM region in CESM}

Negative vegetation-precipitation feedbacks across the Sahel in spring-summer are revealed in CESM from both the dynamical experiments $\left(\mathrm{EXP}_{\mathrm{LAI}}\right.$ and $\left.\mathrm{EXP}_{\mathrm{SOIL}}\right)$ and statistical assessments (Fig. 7). Positive Sahel LAI anomalies cause enhanced ET, mainly because of increased canopy transpiration, leading to increased latent heat flux to the atmosphere and decreased Bowen ratio, which causes surface and low-level cooling. The low-level cooling and increased atmospheric stability, indicated by decreased PBLH and anomalous descending motion in the low-to-middle troposphere, inhibit deep convection (as indicated by an increase in outgoing longwave radiation), which causes reduced rainfall, particularly in the pre- and early-monsoon season. In addition to the increased atmospheric stability, the low-level cooling also causes a decrease in land-ocean heat contrast, which leads to a delayed and weakened monsoon that contributes to the drying in response to positive LAI anomalies. Negative soil moisture-rainfall feedbacks, associated with a change in the circulation of the premonsoon-early monsoon, were also identified in NCAR CCSM4 (Berg et al. 2017). There is no evidence from either the dynamical experiments or statistical GEFA for substantial moisture, momentum, or albedo feedbacks triggered by vegetation anomalies, as opposed to the conclusion about positive vegetationrainfall feedbacks in previous modeling studies (Charney 1975; Zeng et al. 1999; Wang et al. 2004). The two stepwise selection methods yield nearly identical estimates of the local terrestrial impacts on the atmosphere over the Sahel. The relative difference in responses [(forward minus backward) divided by forward multiplied by $100 \%$ ] are within 3\% for all atmospheric variables under consideration, with no noticeable difference in statistical significance. The highly consistent responses according to both stepwise selection methods are attributed to the nearly identical choice of forcings by both approaches, indicating that the dominant forcings for the Sahel largely overwhelm the other forcings. In summary, enhanced atmospheric 

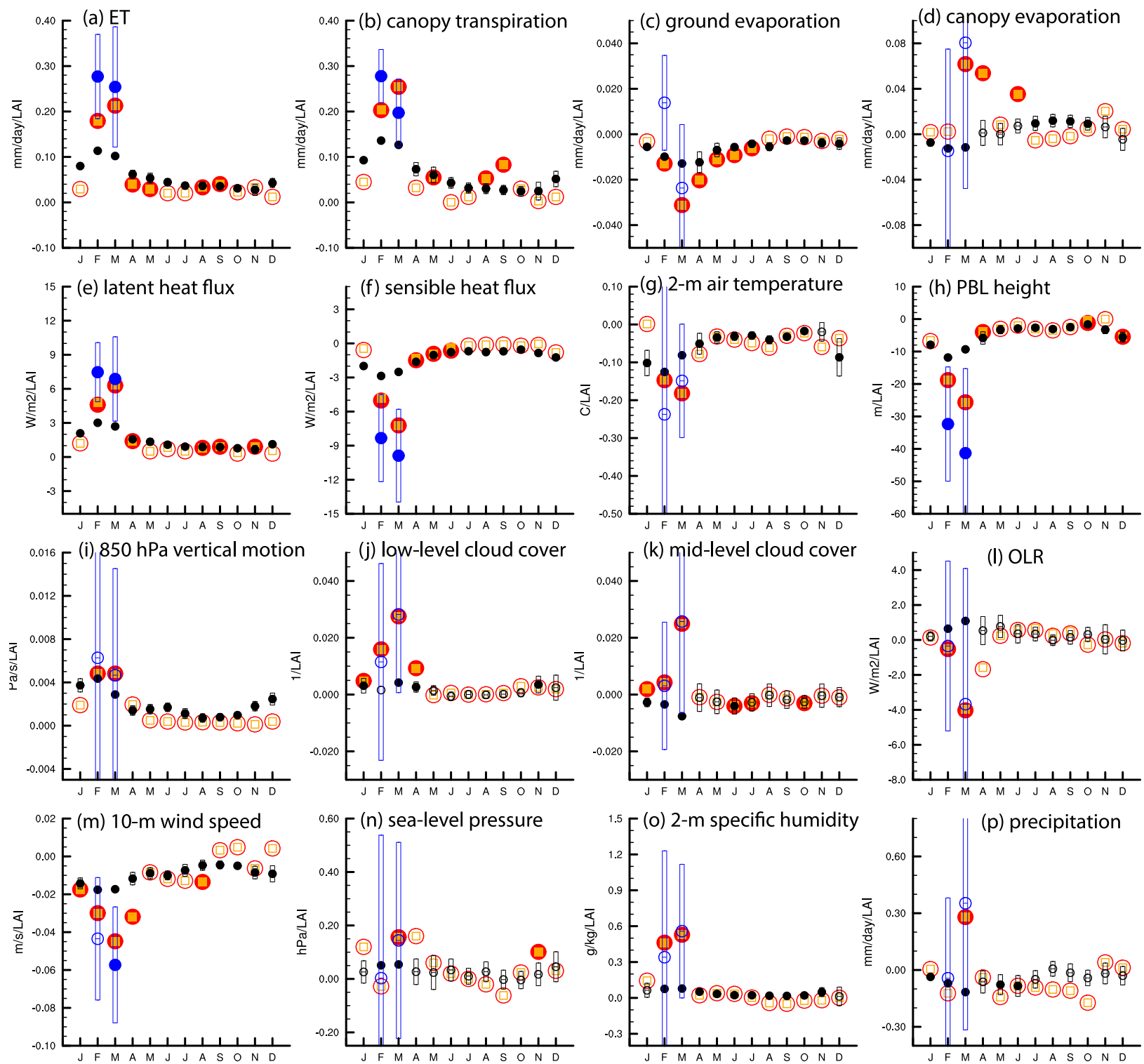

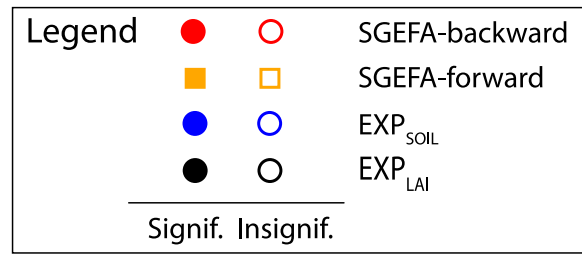

FIG. 8. As in Fig. 7, but for the WAM region.

stability associated with an increase in Sahel LAI and soil moisture overcomes the moisture, momentum, and albedo feedbacks, leading to a negative vegetation-precipitation feedback across the Sahel in CESM, as revealed consistently by both SGEFA and the dynamical experiments.

In contrast to the Sahel, weak positive vegetationprecipitation feedbacks are present across the WAM region during the dry season in CESM, according to both the dynamical experiments and statistical assessments (Fig. 8). The positive vegetation-rainfall feedbacks in the WAM region during the dry season are largely due to the moisture recycling mechanism. Positive LAI anomalies and associated wet soil favor enhanced ET, largely attributed to increased canopy transpiration, which leads 

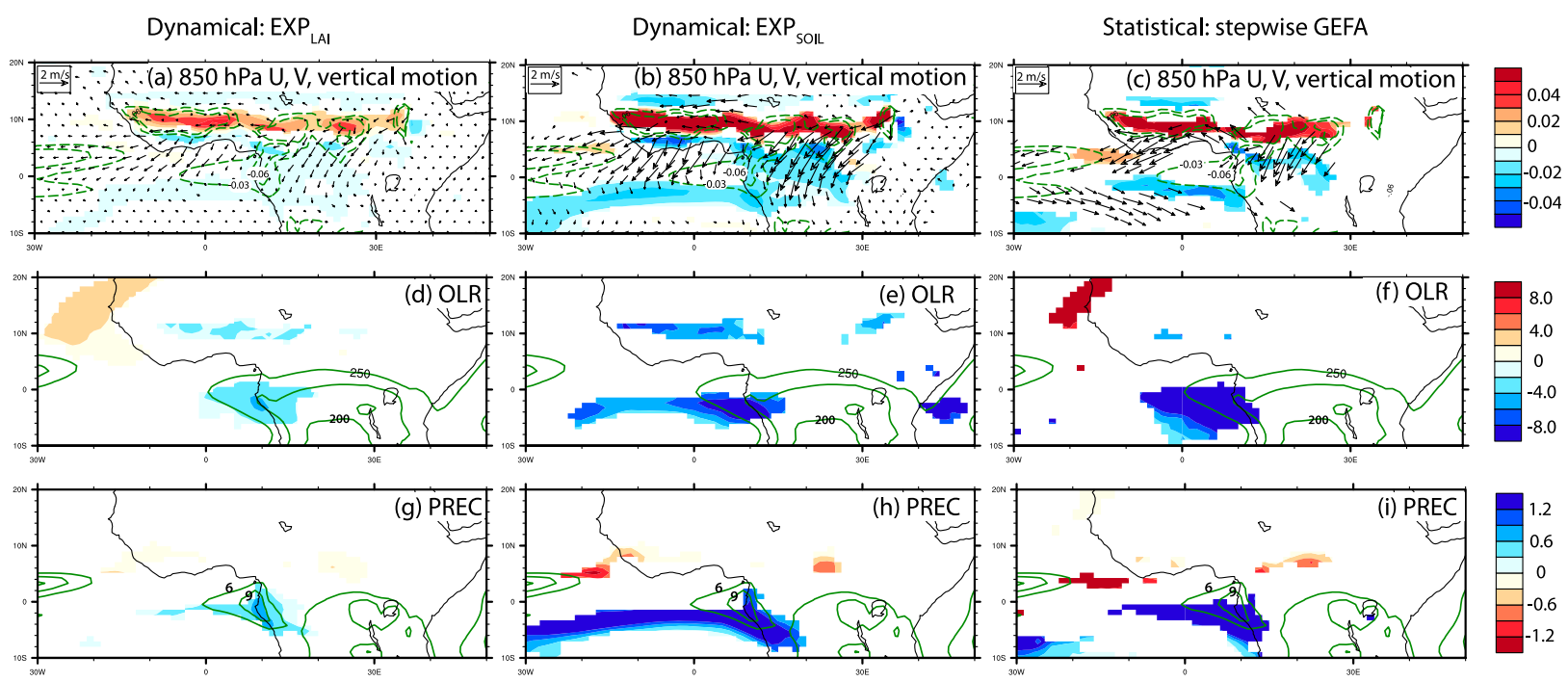

FIG. 9. Dynamically and statistically assessed responses to LAI anomalies across the Sahel in December. Response fields include (a)-(c) 850-hPa wind ( $\mathrm{m} \mathrm{s}^{-1} \mathrm{LAI}^{-1}$; vector) and vertical motion $\left(\mathrm{Pa} \mathrm{s}^{-1} \mathrm{LAI}^{-1}\right.$; shading), (d)-(f) outgoing longwave radiation (OLR) ( $\mathrm{W} \mathrm{m}^{-2} \mathrm{LAI}^{-1}$; shading), and (g)-(i) and PREC (mm day ${ }^{-1} \mathrm{LAI}^{-1}$; shading). Climatology of December 850-hPa vertical motion (Pa s $\left.{ }^{-1}\right)$, OLR $\left(\mathrm{Pa} \mathrm{s}^{-1}\right)$, and PREC $\left(\mathrm{mm} \mathrm{day}^{-1}\right)$ in the fully coupled CESM control run are shown in (a)-(c), (d)-(f), and (g)-(i), respectively, with

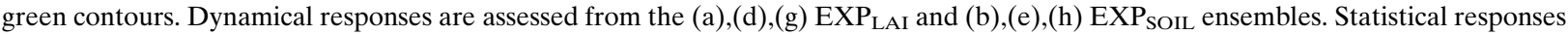
are assessed based on (c),(f),(i) SGEFA using backward selection. Forward selection yields almost identical plots as backward selection shown here. Only statistically significant responses are shown based on the Student's $t$ test and Monte Carlo test $(p<0.1)$ for dynamical and statistical assessments, respectively.

to greater atmospheric moisture, convective activity, and precipitation. Indeed, the positive vegetation-rainfall feedbacks are mostly attributed to the soil moisture anomalies since $\mathrm{EXP}_{\mathrm{LAI}}$, in contrast to $\mathrm{EXP}_{\mathrm{SOIL}}$ and SGEFA, indicates a weak negative precipitation response to positive LAI anomalies in March. In other seasons, the vegetation feedbacks in the WAM region are trivial on most atmospheric variables. Again, the feedbacks obtained through both stepwise selection methods are largely identical.

Remote impacts of the Sahel vegetation on tropical Atlantic rainfall are identified, but limited to December and January in CESM (Fig. 9). In December, positive LAI anomalies and associated wet soil in the Sahel cause local low-level cooling and anomalous subsidence. The cooling leads to an enhanced, and slightly southward-displaced, intertropical convergence zone (ITCZ). In addition, the response of subsidence across the Sahel initiates an anomalous northerly outflow and enhances low-level convergence over the tropical eastern Atlantic Ocean. Again, GEFA captures the combined soil moisture-LAI effects, as the GEFA-based response patterns and magnitudes agree better with those from $\mathrm{EXP}_{\text {SOIL }}$ than $\mathrm{EXP}_{\mathrm{LAI}}$.

\section{Conclusions and discussion}

The reliability of the multivariate statistical method, GEFA, at extracting terrestrial forcings from oceanic forcings on North African regional climate is demonstrated in the current study using CESM. The traditional GEFA approach is refined through stepwise GEFA, in which oceanic and terrestrial forcings that fail to significantly influence the regional climate of North Africa are dropped from the forcing matrix through stepwise selection, thereby reducing the size of the matrix and increasing the accuracy of estimated response fields. By incorporating stepwise selection, GEFA is now capable of accurately capturing terrestrial feedbacks with relatively short datasets, facilitating, for the first time, a convincing observational assessment of vegetationclimate feedbacks across the Sahel (Yu et al. 2017), which has remained an elusive challenge to researchers since the 1970s.

Consistent atmospheric responses to North African LAI anomalies between the statistical GEFA approach, as applied to the CESM control run, and the dynamical approach, based on CESM ensemble experiments, demonstrate GEFA's capacity to successfully extract vegetation feedbacks within the complex Earth system. Stepwise GEFA boasts higher spatial correlations, signal-to-noise ratios, and sign consistency between statistically and dynamically assessed atmospheric responses to land surface anomalies across North Africa than those achieved through traditional GEFA, thereby permitting the reliable estimation of atmospheric response fields through stepwise GEFA even with relatively 
short data records (e.g., as found with many observational products). To accurately capture the seasonal cycle of area-averaged monthly responses on most atmospheric variables, stepwise GEFA needs at least 100 years of data, which is equivalent to about 30 years of data for seasonal responses estimated by aggregating data from the consecutive three months. Both forward and backward SGEFA yield largely consistent results in terms of the selected forcings, consistency with dynamical experiments, and the estimated local terrestrial impacts on the atmosphere over the Sahel and WAM region. GEFA-based atmospheric responses to LAI anomalies are much more consistent in magnitude with the $\mathrm{EXP}_{\text {SOIL }}$ ensemble, in which the coupled soil moisture-LAI in the focal region is modified, than with the $\mathrm{EXP}_{\mathrm{LAI}}$ ensemble, in which only the regional LAI is modified, during months with strong soil moisture-LAI coupling. The higher consistency between the GEFAbased and EXP $_{\text {SOIL }}$-based atmospheric responses indicates that GEFA captures the combined impact of both LAI and soil moisture anomalies on atmospheric conditions. Both GEFA and the dynamical experiments reveal a negative feedback of vegetation on rainfall in the Sahel (because of enhanced atmospheric stability in response to positive LAI anomalies), which is mainly covered by shrubs, trees, and grass, versus a weaker positive feedback in the wetter WAM region (because of intensified moisture recycling), which is primarily covered by trees in CESM.

Although GEFA's capability of successfully extracting terrestrial feedbacks on the atmospheric conditions over both North Africa and North America (Wang et al. 2014) has been demonstrated, further applications of the method should consider the following recommendations. To clearly separate the impacts from correlated forcings, all of the related forcings need to be included in the forcing matrix. For example, in the present study, if WAM LAI, which is correlated with Sahel LAI in most months (temporal correlation of monthly anomalies $\geq 0.28 ; N=300$ ), is not included in the forcing matrix, then the responses in ET, air temperature, atmospheric moisture, and precipitation over the WAM region to Sahel LAI anomalies will not be correctly captured by GEFA as compared with the dynamical experiments. For example, significant positive ET responses to positive Sahel LAI anomalies incorrectly appear across the WAM region when WAM LAI is absent from the forcing matrix, but these significant ET responses across the WAM region correctly disappear if WAM LAI is included in the forcing matrix. Therefore, when applying GEFA to assess the oceanic and terrestrial controls on regional climate, all of the forcings that are of interest, as well as other forcings that are closely related to them, need to be included in the forcing matrix. Similar to multiple linear regression, successful application of GEFA should require existing knowledge of the potential forcings of the focal regional climate. In assessing terrestrial impacts, it is recommended to first identify regions that have moderate-to-high correlations with the focal region in monthly LAI anomalies before determining the GEFA forcing matrix. This can be done by correlating the areaaveraged LAI anomalies across the focal region with LAI anomalies at each grid cell across the globe. Beyond additional LAI forcings to be considered in the forcing matrix, the potential impacts of other land surface forcings (e.g., snow and ice cover) on the assessed vegetation feedbacks over the high-latitude regions need to be explored in future GEFA validation and application studies. In terms of the choice of the stepwise selection method, the application of both forward and backward selection is recommended to ensure that the selected forcings are truly important. Although these two methods yield a largely identical set of key forcings in the present CESM study, likely resulting from the highly overwhelming oceanic and terrestrial forcings for the two focal North African subregions, the results could potentially differ between these two methods when applied to another study region. In the case of inconsistent forcings selected by these two methods, both-way selection, which combines the forward and backward selection approaches, also provides an independent check (Hocking 1976).

Although GEFA successfully predicts both the sign and magnitude of the terrestrial feedbacks across North Africa in the model, the statistical significance is usually weaker in GEFA than in the dynamical experiments, especially $\mathrm{EXP}_{\mathrm{LAI}}$. The application of different significance tests, namely, the Monte Carlo bootstrap method for GEFA versus the Student's $t$ test for the dynamical experiments, is not a likely cause for this discrepancy, since the alternative application of the Monte Carlo bootstrap method to the dynamical experiments yields nearly the same significance levels as indicated by the Student's $t$ test. Likely reasons for the weaker significance in GEFA-based estimates include 1) larger magnitudes of terrestrial forcings in the dynamical assessment than in the statistical assessment, given that extreme anomalies (5th and 95th percentiles) are applied in the dynamical experiments for computational efficiency while GEFA considers the full spectrum of forcing magnitudes from the control run to estimate the feedbacks, and 2) insufficient length of CTRL (300 yr) for application to GEFA to obtain significant responses, especially for those variables (e.g., sea level pressure) that are less directly affected by terrestrial anomalies. 
The assessed terrestrial feedbacks in CESM across North Africa appear to contradict with observations. Across the Sahel, positive vegetation-rainfall feedbacks resulting from the moisture recycling mechanism, particularly in the late-monsoon-postmonsoon season, are revealed in observations by GEFA (Yu et al. 2017) in contrast to the negative vegetation-rainfall feedbacks resulting from the atmospheric stabilization mechanism in CESM. This is not the first time that negative vegetation-rainfall feedbacks across North Africa have been identified in a modeling study. For example, Notaro et al. (2011) simulated an increase in postmonsoon rainfall in response to negative LAI anomalies over the North African monsoon region with CCSM3.5, a CESM predecessor. Negative vegetation-rainfall feedbacks were also identified during the mid-Holocene in the Fast Ocean Atmosphere Model-Lund Potsdam Jena dynamic global vegetation model (FOAM-LPJ) (Notaro and Liu 2008). Potential reasons for the inconsistent land surface feedbacks between models and observations include slight differences in the specified boundaries of the focal geographic region, differences in land-cover type between the simulation and observations (Fig. 2), unrealistic simulation of the annual cycle of LAI (Fig. 4), and unrealistic simulation of the responses in surface albedo, turbulent fluxes, and roughness to land surface anomalies. Indeed, such model deficiencies in the representation of terrestrial feedbacks, as indicated by the application of CESM in the current study and CCSM3.5 in the previous study (Notaro et al. 2011), motivate the evaluation of coupled Earth system models against the observational benchmark established by Yu et al. (2017). Since the current study focuses on GEFA methodology, we leave investigations of the model biases that lead to the inconsistent land surface feedbacks between CESM and observations to an independent study.

By applying GEFA to both observational datasets and coupled Earth system model output, the observed and simulated sign and strength of vegetation-climate feedbacks will be quantified. A comparison of the observed and simulated vegetation feedbacks on various atmospheric variables will help elucidate potential sources of model biases, thereby benefiting future model development and improvement. In addition, the intercomparison of the accuracy of simulated vegetationatmosphere feedbacks (along with ocean-atmosphere feedbacks) among the state-of-the-art Earth system models will facilitate effective model weighting for more reliable regional climate projections.

While the current study has demonstrated the reliability of GEFA at extracting the terrestrial drivers of North African regional climate, two parallel studies by Wang et al. (2017) and Yu et al. (2017) aim to illustrate
GEFA's reliability in terms of isolating oceanic drivers of North African climate and to apply GEFA to observational data to test the model-based hypothesis of Charney (1975) regarding the traditional vegetationalbedo feedback mechanism across the Sahel. The observational GEFA analysis identifies a positive vegetation-rainfall feedback during the late-monsoon and postmonsoon periods in the Sahel associated with a moisture recycling mechanism ( $\mathrm{Yu}$ et al. 2017). The amplified moisture recycling in response to positive anomalies in observed vegetation greenness is apparently underestimated by CESM, according to both the statistical and dynamical assessments in the current study. Although both GEFA validation studies are performed using CESM, the findings regarding statistical GEFA's reliability and the benefits of SGEFA are independent of the model.

Acknowledgments. This work is funded by U.S. Department of Energy (DOE) Regional and Global Climate Modeling (RGCM) program (Grant DESC0012534) and National Science Foundation (NSF) Climate and Large-Scale Dynamics (CLD) program (Grant AGS-1343904). Computer resources are provided by DOE National Energy Research Scientific Computing Center (NERSC). The authors are thankful for helpful discussions with Dr. Zhengyu Liu and appreciate the assistance from Dr. Jiang Zhu in developing the dynamical experiments in CESM.

\section{REFERENCES}

Akaike, H., 1974: A new look at the statistical model identification. IEEE Trans. Autom. Control, 19, 716-723, https://doi.org/ 10.1109/TAC.1974.1100705.

Berg, A. M., B. R. Lintner, K. L. Findell, and A. Giannini, 2017: Soil moisture influence on seasonality and large-scale circulation in simulations of the West African monsoon. J. Climate, 30, 2295-2317, https://doi.org/10.1175/JCLI-D-15-0877.1.

Betts, A. K., and J. H. Ball, 1997: Albedo over the boreal forest. J. Geophys. Res., 102, 28 901-28 909, https://doi.org/10.1029/ 96JD03876.

Bonan, G. B., 2002: Ecological Climatology: Concepts and Applications. Cambridge University Press, $678 \mathrm{pp}$.

—, D. Pollard, and S. L. Thompson, 1992: Effects of boreal forest vegetation on global climate. Nature, 359, 716-718, https://oi.org/10.1038/359716a0.

Buermann, W., 2002: The impact and response of vegetation to climate at interannual timescales. Ph.D. thesis, Boston University, $140 \mathrm{pp}$.

Charney, J. G., 1975: Dynamics of desert and drought in the Sahel. Quart. J. Roy. Meteor. Soc., 101, 193-202, https://doi.org/ 10.1002/qj.49710142802.

, W. J. Quirk, S. H. Chow, and J. Kornfield, 1977: A comparative study of the effects of albedo change on drought in semiarid regions. J. Atmos. Sci., 34, 1366-1385, https://doi.org/ 10.1175/1520-0469(1977)034<1366:ACSOTE >2.0.CO;2. 
Chen, G., M. Notaro, Z. Liu, and Y. Liu, 2012: Simulated local remote biophysical effects of afforestation over the Southeast United States in boreal summer. J. Climate, 15, 2616-2631, https://doi.org/10.1175/JCLI-D-11-00317.1.

Dirmeyer, P. A., Y. Jin, B. Singh, and X. Yan, 2013: Trends in land-atmosphere interactions from CMIP5 simulations. J. Hydrometeor., 14, 829-849, https://doi.org/10.1175/ JHM-D-12-0107.1.

Doherty, R., J. E. Kutzbach, J. Foley, and D. Pollard, 2000: Fully coupled climate/dynamical vegetation model simulations over northern Africa during the mid-Holocene. Climate Dyn., 16, 561-573, https://doi.org/10.1007/s003820000065.

Efron, B., 1982: The Jackknife, the Bootstrap and Other Resampling Plans. Society for Industrial and Applied Mathematics, $92 \mathrm{pp}$.

Findell, K., P. Gentine, B. R. Lintner, and C. Kerr, 2011: Probability of afternoon precipitation in eastern United States and Mexico enhanced by high evaporation. Nat. Geosci., 4, 434439, https://doi.org/10.1038/ngeo1174.

Flato, G., and Coauthors, 2013: Evaluation of climate models. Climate Change 2013: The Physical Science Basis, T. F. Stocker et al., Eds., Cambridge University Press, 741-866.

Foley, J. A., M. T. Coe, M. Scheffer, and G. L. Wang, 2003: Regime shifts in the Sahara and Sahel: Interactions between ecological and climatic systems in northern Africa. Ecosystems, 6, 524539, https://doi.org/10.1007/s10021-002-0227-0.

Folland, C. K., T. N. Palmer, and D. E. Parker, 1986: Sahel rainfall and worldwide sea temperatures, 1901-85. Nature, 320, 602607, https://doi.org/10.1038/320602a0.

Frankignoul, C., and K. Hasselmann, 1977: Stochastic climate models, Part II: Application to sea-surface temperature anomalies and thermocline variability. Tellus, 29, 289-305, https://doi.org/10.3402/tellusa.v29i4.11362.

Giannini, A., R. Saravanan, and P. Chang, 2003: Oceanic forcing of Sahel rainfall on interannual to interdecadal time scales. Science, 302, 1027-1030, https://doi.org/10.1126/ science.1089357.

, M. Biasutti, and M. M. Verstraete, 2008: A climate modelbased review of drought in the Sahel: Desertification, the regreening and climate change. Global Planet. Change, 64, 119-128, https://doi.org/10.1016/j.gloplacha.2008.05.004

Green, J. K., A. Konings, S. H. Alemohammad, J. Berry, D. Entekhabi, J. Kolassa, J.-E. Lee, and P. Gentine, 2017: Regionally strong feedbacks between the atmosphere and terrestrial biosphere. Nat. Geosci., 10,410-414, https://doi.org/ 10.1038/ngeo2957.

Guo, Z., P. A. Dirmeyer, T. DelSole, and R. D. Koster, 2012: Rebound in atmospheric predictability and the role of the land surface. J. Climate, 25, 4744-4749, https://doi.org/10.1175/ JCLI-D-11-00651.1.

Hasselmann, K., 1976: Stochastic climate models. Part I: Theory. Tellus, 28, 473-485, https://doi.org/10.3402/tellusa.v28i6.11316.

He, Y., and E. Lee, 2016: Empirical relationships of sea surface temperature and vegetation activity with summer rainfall variability over the Sahel. Earth Interact., 20, 1-18, https://doi.org/ 10.1175/EI-D-15-0028.1.

Henderson-Sellers, A., K. McGuffie, and C. Gross, 1995: Sensitivity of global climate model simulations to increased stomatal resistance and $\mathrm{CO}_{2}$ increases. J. Climate, 8, 1738-1756, https://doi.org/ 10.1175/1520-0442(1995)008<1738:SOGCMS > 2.0.CO;2.

Hocking, R. R., 1976: The analysis and selection of variables in linear regression. Biometrics, 32, 1-49, https://doi.org/10.2307/ 2529336.
Hoerling, M. P., J. W. Hurrell, J. Eischeid, and A. Phillips, 2006: Detection and attribution of twentieth-century northern and southern African rainfall change. J. Climate, 19, 3989-4008, https://doi.org/10.1175/JCLI3842.1.

Hoffman, F. M., and Coauthors, 2008: The Carbon-Land Model Project (C-LAMP): A protocol and evaluation metrics for global terrestrial biogeochemistry models. Int. Congress on Environmental Modeling and Software/Fourth Biennial Meeting on Integrating Science and Information Technology for Environmental Assessment and Decision Making, Barcelona, Spain, International Environmental Modeling and Software Society, 1039-1048.

Hunke, E. C., W. H. Lipscomb, A. K. Turner, N. Jeffery, and S. Elliott, 2008: CICE: The Los Alamos Sea Ice Model: Documentation and software, version 4.0. Los Alamos National Laboratory Tech. Rep. LA-CC-06-012, 76 pp.

Hurrell, J. W., and Coauthors, 2013: The Community Earth System Model: A framework for collaborative research. Bull. Amer. Meteor. Soc., 94, 1339-1360, https://doi.org/10.1175/ BAMS-D-12-00121.1.

Jones, H. G., 1983: Plants and Microclimate. Cambridge University Press, $323 \mathrm{pp}$.

Kaufmann, R. K., D. I. Stern, R. B. Myneni, C. J. Tucker, D. Slayback, N. V. Shabanov, and J. Pinzon, 2003: The effect of vegetation on surface temperature: A statistical analysis of NDVI and climate data. Geophys. Res. Lett., 30, 2147, https:// doi.org/10.1029/2003GL018251.

Klein, C., J. Bliefernicht, D. Heinzeller, U. Gessner, I. Klein, and H. Kunstmann, 2017: Feedback of observed interannual vegetation change: A regional climate model analysis for the West African monsoon. Climate Dyn., 48, 2837-2858, https:// doi.org/10.1007/s00382-016-3237-x.

Koster, R. D., and Coauthors, 2004: Regions of strong coupling between soil moisture and precipitation. Science, 305, 11381140, https://doi.org/10.1126/science.1100217.

— , and Coauthors, 2006: GLACE: The Global Land-Atmosphere Coupling Experiment. Part I: Overview. J. Hydrometeor., 7, 590-610, https://doi.org/10.1175/JHM510.1.

- and Coauthors, 2010: The contribution of land surface initialization to subseasonal forecast skill: First results from the GLACE-2 project. Geophys. Res. Lett., 37, L02402, https:// doi.org/10.1029/2009GL041677.

_ - and Coauthors, 2011: The second phase of the Global Land-Atmosphere Coupling Experiment: Soil moisture contribution to subseasonal forecast skill. J. Hydrometeor. 12, 805-822, https://doi.org/10.1175/2011JHM1365.1.

Kutzbach, J. E., G. Bonan, J. Foley, and S. P. Harrison, 1996: Vegetation and soil feedbacks on the response of the African monsoon to orbital forcing in the early to middle Holocene. Nature, 384, 623-626, https://doi.org/10.1038/384623a0.

Lawrence, D. M., and Coauthors, 2011: Parameterization improvements and functional and structural advances in version 4 of the Community Land Model. J. Adv. Model. Earth Syst., 3, M03001, https://doi.org/10.1029/2011MS00045.

Lee, E., Y. He, M. Zhou, and J. Liang, 2015: Potential feedback of recent vegetation changes on summer rainfall in the Sahel. Phys. Geogr., 36, 449-470, https://doi.org/10.1080/ 02723646.2015.1120139.

Liu, Z., M. Notaro, J. Kutzbach, and N. Liu, 2006: Assessing global vegetation-climate feedbacks from observations. J. Climate, 19, 787-814, https://doi.org/10.1175/JCLI3658.1.

- and Coauthors, 2007: Simulating the transient evolution and abrupt change of Northern African atmosphere-ocean-terrestrial 
ecosystem in the Holocene. Quat. Sci. Rev., 26, 1818-1837, https:// doi.org/10.1016/j.quascirev.2007.03.002.

— , N. Wen, and Y. Liu, 2008: On the assessment of nonlocal climate feedback. Part I: The generalized equilibrium feedback assessment. J. Climate, 21, 134-148, https://doi.org/ 10.1175/2007JCLI1826.1.

- M. Notaro, and R. Gallimore, 2010: Indirect vegetation-soil moisture feedback with application to Holocene North Africa climate. Global Change Biol., 16, 1733-1743, https://doi.org/ 10.1111/j.1365-2486.2009.02087.x.

Los, L. O., G. P. Weedon, P. R. J. North, J. D. Kaduk, C. M. Taylor, and P. M. Cox, 2006: An observation-based estimate of the strength of rainfall-vegetation interactions in the Sahel. Geophys. Res. Lett., 33, L16402, https://doi.org/10.1029/2006GL027065.

Lu, J., and T. L. Delworth, 2005: Oceanic forcing of the late 20th century Sahel drought. Geophys. Res. Lett., 32, L22706, https:// doi.org/10.1029/2005GL022980.

Neale, R. B., and Coauthors, 2010: Description of the NCAR Community Atmosphere Model (CAM 5.0). NCAR Tech. Note NCAR/TN-486+ STR, 289 pp.

Notaro, M., and Z. Liu, 2008: Statistical and dynamical assessment of simulated vegetation feedbacks on climate over the boreal forests. Climate Dyn., 31, 691-712, https://doi.org/10.1007/ s00382-008-0368-8.

-, — and J. W. Williams, 2006: Observed vegetation-climate feedbacks in the United States. J. Climate, 19, 763-786, https:// doi.org/10.1175/JCLI3657.1.

_- , Y. Wang, Z. Liu, R. Gallimore, and S. Levis, 2008: Combined statistical and dynamical assessment of simulated vegetationrainfall interactions in North Africa during the mid-Holocene. Global Change Biol., 14, 347-368, https://doi.org/10.1111/ j.1365-2486.2007.01495.x.

_ G. Chen, and Z. Liu, 2011: Vegetation feedbacks to climate in the global monsoon regions. J. Climate, 24, 5740-5756, https:// doi.org/10.1175/2011JCLI4237.1.

— _ _ , Y. Yu, F. Wang, and A. Tawfik, 2017: Regional climate modeling of vegetation feedbacks on the Asian-Australian monsoon systems. J. Climate, 30, 1553-1582, https://doi.org/ 10.1175/JCLI-D-16-0669.1.

O'Brien, K. L., 1996: Tropical deforestation and climate change. Prog. Phys. Geogr., 20, 311-335, https://doi.org/ 10.1177/030913339602000304.

Oleson, K. W., and Coauthors, 2010: Technical description of version 4.0 of the Community Land Model (CLM). NCAR Tech. Note NCAR/TN-478+STR, 266 pp.

Pielke, R. A., Sr., R. Avissar, M. Raupach, A. J. Dolman, X. Zeng, and A. S. Denning, 1998: Interactions between the atmosphere and terrestrial ecosystems: Influence on weather and climate Global Change Biol., 4, 461-475, https://doi.org/10.1046/ j.1365-2486.1998.t01-1-00176.x

Pollard, D., and S. L. Thompson, 1995: The effect of doubling stomatal resistance in a global climate model. Global Planet. Change, 10, 129-161, https://doi.org/10.1016/ 0921-8181(94)00023-7.

Robinson, D. A., and G. Kukla, 1985: Maximum surface albedo of seasonally snow-covered lands in the Northern Hemisphere. J. Climate Appl. Meteor., 24, 402-411, https://doi.org/ 10.1175/1520-0450(1985)024<0402:MSAOSS>2.0.CO;2.

Rodríguez-Fonseca, B., and Coauthors, 2015: Variability and predictability of West African droughts: A review on the role of sea surface temperature anomalies. J. Climate, 28, 4034-4060, https://doi.org/10.1175/JCLI-D-14-00130.1.
Roehrig, R., D. Bouniol, F. Guichard, F. Hourdin, and J.- L. Redelsperger, 2013: The present and future of the West African monsoon: A process-oriented assessment of CMIP5 simulations along the AMMS transect. J. Climate, 26, 64716504, https://doi.org/10.1175/JCLI-D-12-00505.1.

Rowell, D. P., 2003: The impact of Mediterranean SSTs on the Sahelian rainfall season. J. Climate, 16, 849-862, https:// doi.org/10.1175/1520-0442(2003)016<0849:TIOMSO > 2.0.CO;2.

Santanello, J. A., C. D. Peters-Lidard, and S. V. Kumar, 2011: Diagnosing the sensitivity of local land-atmosphere coupling via the soil moisture-boundary layer interaction. J. Hydrometeor., 12, 766-786, https://doi.org/10.1175/JHM-D-10-05014.1.

Segele, Z. T., M. B. Richman, L. M. Leslie, and P. J. Lamb, 2015: Seasonal-to-interannual variability of Ethiopia/Horn of Africa monsoon. Part II: Statistical multimodel ensemble rainfall predictions. J. Climate, 28, 3511-3536, https://doi.org/10.1175/ JCLI-D-14-00476.1.

Shukla, J., and Y. Mintz, 1982: Influence of land-surface evapotranspiration on the Earth's climate. Science, 215, 1498-1501, https://doi.org/10.1126/science.215.4539.1498.

Smith, R., and Coauthors, 2010: The Parallel Ocean Program (POP) reference manual: Ocean component of the Community Climate System Model (CCSM) and Community Earth System Model (CESM). Los Alamos National Laboratory Rep. LAUR-10-01853, http://www.cesm.ucar.edu/models/ cesm1.0/pop2/doc/sci/POPRefManual.pdf.

Sud, Y. C., and W. E. Smith, 1985: The influence of surface roughness of deserts on the July circulation. Bound.-Layer Meteor., 33, 15-49, https://doi.org/10.1007/BF00137034.

_- J. Shukla, and Y. Mintz, 1988: Influence of land-surface roughness on atmospheric circulation and precipitation: A sensitivity study with a general circulation model. J. Appl. Meteor., 27, 1036-1054, https://doi.org/10.1175/1520-0450(1988)027<1036: IOLSRO $>2.0 . \mathrm{CO} ; 2$

Sun, S., and G. Wang, 2012: The complexity of using a feedback parameter to quantify the soil moisture-precipitation relationship. J. Geophys. Res., 117, D11113, https://doi.org/ 10.1029/2011JD017173.

Wang, F., Z. Liu, and M. Notaro, 2013: Extracting the dominant SST modes impacting North America's observed climate. J. Climate, 26, 5434-5452, https://doi.org/10.1175/JCLI-D-12-00583.1.

- M. Notaro, Z. Liu, and G. Chen, 2014: Observed local and remote influences of vegetation on the atmosphere across North America using a model-validated statistical technique that first excludes oceanic forcings. J. Climate, 27, 362-382, https://doi.org/10.1175/JCLI-D-13-00080.1.

Y. Yu, M. Notaro, J. Mao, X. Shi, and Y. Wei, 2017: Advancing a model-validated statistical method for decomposing the key oceanic drivers of regional climate: Focus on North African climate variability in CESM. J. Climate, 27, 362-382, https://doi.org/10.1175/JCLI-D-13-00080.1.

Wang, G., E. A. B. Eltahir, J. A. Foley, D. Pollard, and S. Levis, 2004: Decadal variability of rainfall in the Sahel: Results from the coupled GENESIS-IBIS atmosphere-biosphere model. Climate Dyn., 22, 625-637, https://doi.org/10.1007/ s00382-004-0411-3.

Wen, N., Z. Liu, Q. Y. Liu, and C. Frankignoul, 2010: Observed atmospheric responses to global SST variability modes: A unified assessment using GEFA. J. Climate, 23, 1739-1759, https://doi.org/10.1175/2009JCLI3027.1.

,$- \frac{}{-}$, and -2013 : Observational assessment of nonlocal heat flux feedback in the North Atlantic by GEFA. J. Appl. 
Meteor. Climatol., 52, 645-653, https://doi.org/10.1175/ JAMC-D-11-0257.1.

Wonnacott, T. H., and R. J. Wonnacott, 1972: Introductory Statistics. Wiley, 622 pp.

Yin, L., R. Fu, Y. F. Zhang, P. A. Arias, D. N. Fernando, W. Li, K. Fernandes, and A. R. Bowerman, 2014: What controls the interannual variation of the wet season onsets over the Amazon? J. Geophys. Res. Atmos., 119, 2314-2328, https://doi.org/ 10.1002/2013JD021349.

Yu, Y., M. Notaro, Z. Liu, F. Wang, F. Alkolibi, E. Fadda, and F. Bakhrjy, 2015: Climatic controls of the interannual to decadal variability in Saudi Arabian dust activity: Toward the development of a seasonal prediction model. J. Geophys. Res. At mos., 120, 1739-1758, https://doi.org/10.1002/2014JD022611.

- — - F. Wang, J. Mao, X. Shi, and Y. Wei, 2017: Observed vegetation-climate feedbacks in the Sahel: Is the classic albedo feedback mechanism truly dominant? Nat. Commun., 8, 1873, https://doi.org/10.1038/s41467-017-02021-1.

Zeng, N., J. D. Neelin, K.-M. Lau, and C. J. Tucker, 1999: Enhancement of interdecadal climate variability in the Sahel by vegetation interaction. Science, 286, 1537-1540, https://doi.org/ 10.1126/science.286.5444.1537. 